\title{
Rapid changes in ocean circulation and atmospheric radiocarbon
}

\author{
Thomas F. Stocker \\ Climate and Environmental Physics, Physics Insitute, University of Bern, Bern, Switzerland
}

Daniel G. Wright

Department of Fisheries and Oceans, Bedford Institute of Oceanography

Dartmouth, Nova Scotia, Canada

\begin{abstract}
.
A latitude-depth, coupled global ocean-ice-atmosphere model is extended to include a simple biosphere component. A physically reasonable adjustment of runoff into the North Atlantic is invoked to achieve a transient response to glacial meltwater perturbations, which closely resembles the Younger Dryas climate event. We then investigate the evolution of the isotopic ratio of atmospheric radiocarbon, $\Delta^{14} \mathrm{C}$, due to the rapid changes of deep ocean circulation. When the North Atlantic branch of the conveyor belt circulation is interrupted, the oceanic uptake of radiocarbon is reduced, resulting in an increase of atmospheric $\Delta^{14} \mathrm{C}$ by about $35 \%$. The reduction of ventilation in the North Atlantic is partly compensated by an increase of the ${ }^{14} \mathrm{C}$ ratios of the biosphere, the Southern Ocean, and the upper ocean above $1000 \mathrm{~m}$ depth. A plateau of the ${ }^{14} \mathrm{C}$ year/calendar year relation can be generated at the time of the rapid reinitiation of deep ocean ventilation which begins coincident with the major temperature increase and lasts for about 60 years. It is hence significantly shorter than that found by analyzing tree rings during the termination of Younger Dryas (longer than 400 years). A sensitivity study reveals that the duration of the plateau depends strongly on the transient evolution of the gas cxchange rate and can increase to $150-300$ years if changes of $p \mathrm{CO}_{2}$ or sea ice coverage are taken into account.
\end{abstract}

\section{Introduction}

The activity of radiocarbon is a powerful means to assign a timescale to paleoclimatic records obtained from the analysis of a multitude of sources, such as tree rings, coral reefs, and sea and lake sediments. However, the accuracy of this technique may be seriously affected by changes of the atmospheric concentration of radiocarbon, ${ }^{14} C^{\mathrm{atm}}$. There are two processes which significantly influence the temporal evolution of ${ }^{14} C^{\mathrm{atm}}$. First, variability in the flux of cosmic rays and changes in the Earth's magnetic field can change the production rate of radiocarbon in the atmosphere. The observed general decrease of ${ }^{14} C^{\text {atm }}$ in the late Holocene until about $1500 \mathrm{yr}$ B.P. is thought to be the result of a decrease in the production rate by about 30\% [Damon

Copyright 1996 by the American Geophysical Union.

Paper number 96PA02640.

0883-8305/96/96PA-02640\$12.00 et al., 1978; Siegenthaler et al., 1980; Peng, 1989; Stuiver and Braziunas, 1993]. Beer et al. [1988] used variations in production rates derived from ${ }^{10} \mathrm{Be}$ concentrations in ice cores to show that ${ }^{14} C^{\text {atm }}$ changes of about $20 \%$ can occur on timescales of about 200 years. After about 5000 yr B.P., a large fraction of the ${ }^{14} \mathrm{C}$ variability based on tree rings can be explained by production variations estimated from the Be record. Owing to insufficient resolution of the Be data before $5000 \mathrm{yr}$ B.P., reconstruction of such fluctuations is not possible. A second mechanism for short-term variability of ${ }^{14} C^{\text {atm }}$ involves variability in the sizes of and exchange rates between the radiocarbon reservoirs. These are strongly affected by the ventilation rate of the world ocean by the thermohaline circulation (THC) because the ocean contains more than $90 \%$ of the global ${ }^{14} \mathrm{C}$ inventory. If this circulation changes, uptake rates of radiocarbon by the ocean are modified and can result in variations in ${ }^{14} C^{\text {atm }}$ which are recorded in high-resolution paleoclimatic archives. 
If ${ }^{14} C^{\text {atm }}$ diminishes at the rate of the natural decay, accurate age determination is impossible during that period because all organic material whose ${ }^{14} \mathrm{C}$ content was set during that time has the same apparent age. This is evident as an "age plateau" when calendar age (absolute timescale) is plotted against ${ }^{14} \mathrm{C}$ age. Such plateaus have been found in European peat bogs [Oeschger et al., 1980], lake sediments [Zbinden et al., 1989; Lotter, 1991; Hajdas et al., 1993; Goslar et al., 1995], in tree rings [Becker et al., 1991; Kromer and Becker, 1995], and in corals [Bard et al., 1990; Edwards et al., 1993]. The most accurate record at present is the German oak/pine master choronology by Kromer and Becker [1993], whose oldest part was updated recently (S. Björck et al., Synchronised Younger DryasPreboreal records give new insights about climate related ocean ventilation changes, submitted to Science, 1996 (hereinafter referred to as S. Björck et al., submitted manuscript, 1996); B. Kromer, personal communication, 1996). The longest time of reduced increase of radiocarbon age relative to calendar age occurs close to the Younger Dryas/Preboreal boundary, a rapid transition from a cold to a warm phase, and is referred to as the $10,000{ }^{14} \mathrm{C}$ year plateau (Figure 1, grey box). This phase lasts for at least 400 years and consists of two subplateaus separated by a time of slow increase of the radiocarbon age.

The main purpose of this paper is to investigate to what extent changes in the THC can influence ${ }^{14} C^{\text {atm }}$ in order to give bounds on changes that are caused by the transient deep ocean circulation. To this end, the physical-geochemical model of Stocker et al. [1994] is supplemented with a biosphere component. Although the ocean has simplified dynamics which focus on the zonally averaged part of the THC [Wright and Stocker, 1991; Wright et al., 1995], the steady state solutions and the transient behavior of this model are consistent with results from three-dimensional ocean models (OGCM) [Bryan, 1986; Maier-Reimer and Mikolajewicz, 1989; Mikolajewicz and Maier-Reimer, 1994] and coupled atmosphere-ocean general circulation models (A/OGCM) [Manabe and Stouffer, 1988; Manabe and Stouffer, 1995]. A recent study by U. Mikolajewicz (A meltwater-induced collapse of the 'conveyor belt' thermohaline circulation and its influence on the distribution of $\Delta^{14} \mathrm{C}$ and $\delta^{18} \mathrm{O}$ in the oceans, submitted to Journal of Geophysical Research, 1996 (hereinafter referred to as U. Mikolajewicz, submitted manuscript, 1996) also addresses the impact of ventilation changes on ${ }^{14} C^{\mathrm{atm}}$.

There is compelling observational evidence that the ocean has the potential to change rapidly between different flow regimes and so influences climate on a regional to hemispheric scale [Broecker and Denton, 1989]. The last major example of these abrupt events is the Younger Dryas cold event (hereinafter referred to as

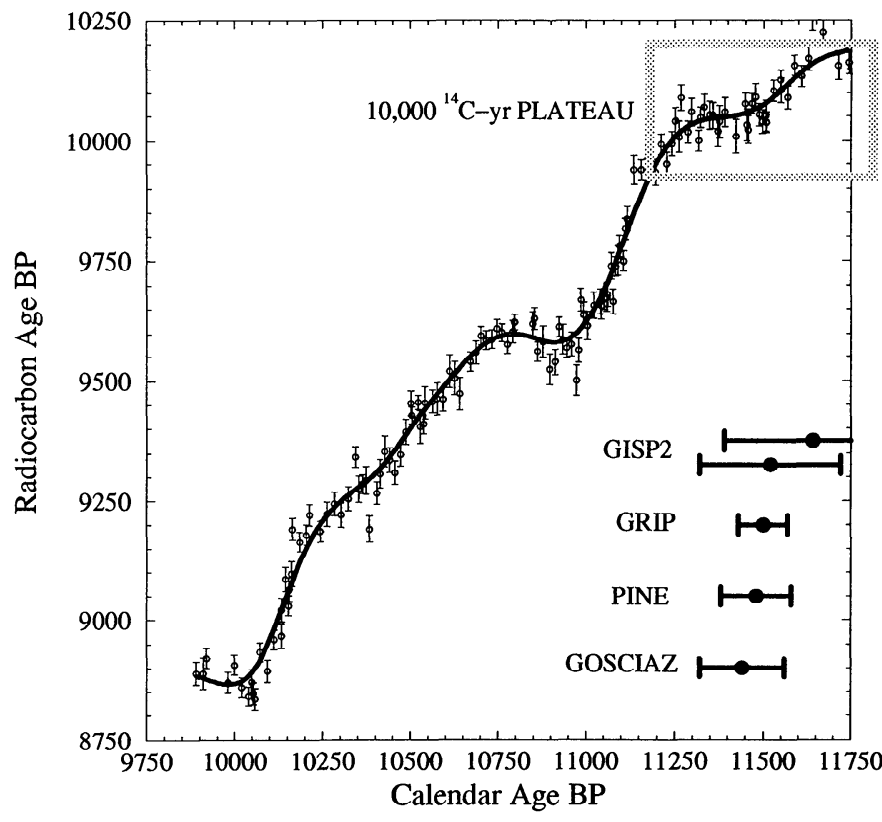

Figure 1. Oldest part of the radiocarbon calibration curve derived from the combined oak/pine German master chronology by Kromer and Becker [1993] and recently corrected by B. Kromer (personal communication, 1996) showing a short age plateau at 9,600 ${ }^{14} \mathrm{C}$ years and the extended period of strongly reduced radiocarbon age increase referred to as the $10,000{ }^{14} \mathrm{C}$ year plateau (grey box). The beginning of the pine chronology $\left(8,800{ }^{14} \mathrm{C}\right.$ years) is tied to the oak chronology through the long-term ${ }^{14} \mathrm{C}$ trend. Recent estimates of the termination of the Younger Dryas (YD) event are indicated by the horizontal bars. The $10,000{ }^{14} \mathrm{C}$ year plateau ends about 300 years after the termination of the YD based on the pine tree ring width (S. Björck, submitted manuscript, 1996) or 300-450 years after the termination according to the dating of the two Greenland ice corcs [Johnsen et al., 1992; Alley et al., 1993]. Data from Polish lake Gościąż show that the $10,000{ }^{14} \mathrm{C}$ year plateau ends 250 years after the termination of Younger Dryas [Goslar et al., 1995]. All estimates are in close agreement and indicate that the $10,000{ }^{14} \mathrm{C}$ year plateau extended a few hundred years beyond the cold-warm transition at the end of YD (calibration curve supplied by B. Kromer (personal communication, 1996)).

YD). According to the analyses of the dust content in ice cores [Dansgaard et al., 1989; Taylor et al., 1993], YD initiated over a period of order a few decades to 100 years, lasted for about 1300 years, and terminated in a few decades or less. It has been suggested [Oeschger et al., 1984; Broecker et al., 1985a; Broecker et al., 1988; Lehman and Keigwin, 1992] that this event was due to a temporary weakening or cessation of the overturning circulation in the Atlantic basin, and previous modeling work supports this hypothesis [MaierReimer and Mikolajewicz, 1989; Wright and Stocker, 1993; Lehman et al., 1993; Sakai and Peltier, 1996]. 
The paleoceanographic data, mainly based on isotope concentrations $\left(\delta^{18} \mathrm{O}, \delta^{13} \mathrm{C}\right)$ as well as abundances determined from planktonic and benthic foraminifera species, are controversial at present. Jansen and Veum [1990] and Veum et al. [1992] do not find reduced $\delta^{13} \mathrm{C}$ values of benthic foraminifera in two cores from the North Atlantic and the Norwegian Sea, as would be expected if the supply of nutrient-depleted North Atlantic Deep Water (NADW) were interrupted during the YD. On the basis of data from 95 deep-sea cores, Sarnthein et al. [1994] produced latitude-depth maps of $\delta^{13} \mathrm{C}$ of benthic foraminifera for different times during the last $30 \mathrm{kyr}$. Generally, they confirm earlier findings that NADW formation was greatly reduced during the last glacial maximum [Duplessy et al., 1988]. The time slice closest to or within YD $(12,300-12,800 \mathrm{yr}$ B.P.) exhibits values of $\delta^{13} \mathrm{C}>1.2 \%$ at depths down to about $2 \mathrm{~km}$ north of $40^{\circ}$ N. Sarnthein et al. [1994] interpret this as a circulation mode with NADW formation, perhaps somewhat weaker than in the early Holocene. Koç et al. [1993] find that the coastal area of Norway was ice free during the YD, suggesting continued inflow of Atlantic waters.

On the other hand, numerous paleoclimatic reconstructions confirm a direct link betwcen high-latitude temperatures derived from ice cores and conditions in the surface and deep ocean [Broecker and Denton, 1989; Bond et al., 1993; Keigwin and Lehman, 1994; Bard et al., 1994]. Coupled ocean circulation-biogeochemical models are a quantitative means to assess the transient behavior of $\delta^{13} \mathrm{C}$ during rapid changes of the ocean circulation.

Switches of the North $\Lambda$ tlantic THC are at present the only viable explanation for the amplitudes and rapidity of climate change evident in the numerous paleoarchives. This suggestion is supported by the fact that abrupt climate changes appear most pronounced in the North Atlantic region. Numerous ocean and climate models have demonstrated this quantitatively [Maier-Reimer and Mikolajewicz, 1989; Stocker et al., 1992; Wright and Stocker, 1993; Lehman et al., 1993; Sakai and Peltier, 1996]. However, it should be noted that there is evidence that YD and similar abrupt climatic events (Heinrich events and Dansgaard/Oeschger oscillations) may be of hemispheric or even global extent [Chappellaz et al., 1993; Denton and Hendy, 1994; Broecker, 1994], although the exact phase relation between northern and southern hemispheric changes remains to be determined.

The phase relation between climatic variables (e.g., North Atlantic sea surface temperature, atmospheric temperatures) and changes in ${ }^{14} C^{\text {atm }}$ provides important constraints for a possible mechanism of YD. In Figure 1 we summarize the datings of the YD termination and compare them with the temporal location of the ${ }^{14} \mathrm{C}$ age plateau. These newest dates suggest that the plateau started near the end of YD and ended a few hundred years after YD. This is central to the discussion on the mechanism responsible for this abrupt climatic event. The resumption of the THC in the North Atlantic and enhanced ventilation of the deep ocean at the termination of YD could account for the amplitude and rapidity of temperature increases and would imply that the plateau starts near the end of YD as shown in this paper.

\section{Ocean Influence on the Radiocarbon Clock}

The age estimated by radiocarbon dating is determined under the assumption that the initial concentration of radiocarbon in the atmosphere is a known value, ${ }^{14} C^{\mathrm{atm}}$, corresponding to a known global inventory, $I$, determined by the rate of production of radiocarbon in the stratosphere. In reality, the atmosphere, biosphere, and ocean inventories also vary as a result of exchanges between these reservoirs. To focus on the effect of such reservoir exchanges, the global rate of production of radiocarbon is kept constant in all experiments discussed here. Hence the global inventory of radiocarbon is time independent, and any age anomalies are due solely to reservoir exchanges.

Before discussing model results, it is instructive to illustrate the anticipated cffects. Let $\tau$ represent the actual time at which radiocarbon is sequestered from the atmosphere, and let $\tau_{a}$ be the apparent time based on the assumption that the atmospheric inventory is time independent. Here $\tau$ and $\tau_{a}$ are related by

$$
I_{A}^{0} \times \mathrm{e}^{-\lambda\left(t-\tau_{a}\right)}=I_{A}(\tau) \times \mathrm{e}^{-\lambda(t-\tau)},
$$

where $I_{A}^{0}$ is the constant atmospheric inventory that would obtain in the absence of changes in reservoir inventories, $I_{A}(\tau)$ is the actual inventory at time $\tau, t$ is the time at which measurements are made, and $\lambda^{-1}$ is the e-folding time for the decay of radiocarbon ( 8267 years). Hence

$$
\tau_{a}=\tau+\frac{1}{\lambda} \ln \left(\frac{I_{A}(\tau)}{I_{A}^{0}}\right) .
$$

Differentiating with respect to $\tau$ gives the speed at which the radiocarbon clock advances:

$$
\frac{\partial \tau_{a}}{\partial \tau}=1+\frac{1}{\lambda} \frac{1}{I_{A}(\tau)} \frac{\partial I_{A}(\tau)}{\partial \tau} .
$$

For an ideal representation of age, the second term on the right side of equation (2) must either vanish or be known. Defining the "slowdown" of the radiocarbon clock as

$$
Q_{S}=100 \% \times\left(1-\frac{\partial \tau_{a}}{\partial \tau}\right),
$$

a full age plateau has $Q_{S}=100 \%$; we will use the time 
period for which $Q_{S}>70 \%$ as a measure for the duration of a plateau.

The effect of time-dependent reservoir sizes is often assumed to be negligible, but it is clcar from cquation (3) that if the atmospheric inventory is increased (decreased) by exchange with the ocean or the biosphere, then the clock speed is increased (decreased). In fact, since the ocean inventory is approximately 60 times that of the atmosphere, a $0.1 \%$ change in ocean inventory over 500 years could change the speed of the radiocarbon clock by $100 \%$ ! (Note that this estimation is permitted for ${ }^{14} \mathrm{C}$ because to first order in the fractionation factors, the buffer factor of sea surface carbon chemistry does not influence isotopic atmosphere-ocean exchange of carbon). Even if the effect of the biosphere is taken into account, the change in ocean inventory required to create a $100 \%$ change in the speed of the radiocarbon clock is still only a few tenths of a percent. A useful clock thus requires a very stable ocean inventory. Indced, based on this simple estimate, one might suggest that the ocean circulation could not have changed very significantly, or changes in the speed of the radiocarbon clock would have been much greater than recent estimates suggest. Such arguments turn out to be wrong. Our quantitative estimates based on YD model simulations show that very substantial changes in ocean circulation are accompanied by rather modest changes in total ocean inventory, and the magnitude of the resulting changes in the speed of the radiocarbon clock are consistent with observational estimates.

\section{Model Spin-Up and Steady State}

The ocean component is a modified version of the zonally averaged ocean circulation model of Wright and Stocker [1992]. Pacific, Atlantic, and Indian Ocean basins are each represented by zonally averaged equations of motion and coupled through the Southern Ocean (Figure 2). The model is coupled to an energy balance model of the atmosphere and a tracer component [Stocker et al., 1994]. Modeling radiocarbon also requires biospheric reservoirs. We have included the simple four-box biosphere of Siegenthaler and Oeschger [1987] with constant carbon exchange fluxes. The model and some modifications to earlier versions are described in the appendix.

For the spin-up, surface values of temperature and salinity are restored to the $30-\mathrm{m}$ estimates of Levitus [1982], zonal wind stress is taken from Han and Lee [1983], and the atmospheric radiocarbon concentration ${ }^{14} C^{\text {atm }}$ is held constant at the value corresponding to the standard ${ }^{14} \mathrm{C} /{ }^{12} \mathrm{C}$ ratio, i.e., at $\Delta^{14} \mathrm{C}=0 \%$. Temperature, salinity, stream function, and $\Delta^{14} \mathrm{C}$ are broadly consistent with obscrvations (Figurc 3 ). Thesc results are similar to previous results obtained with

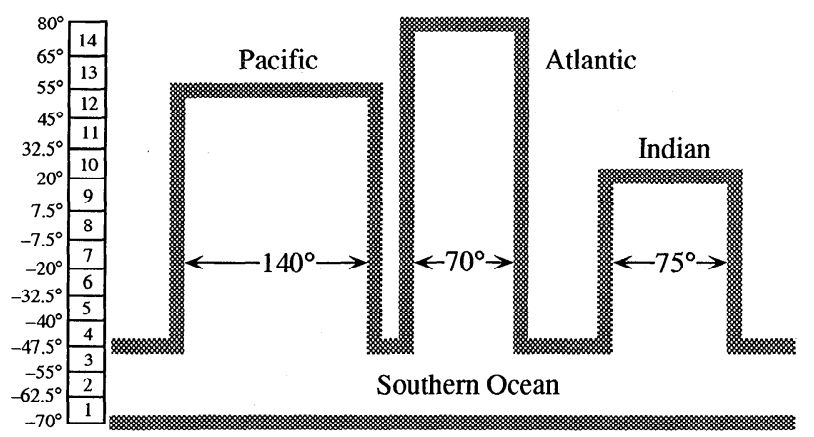

Figure 2. Geometry and resolution of the oceanic component of the climate model. Each ocean basin has area and volume that is within $5 \%$ of the observed estimates. The latitudinal resolution is shown to the left, and the vertical resolution is given in Table A1.

this model using a simpler velocity parameterization, constant vertical diffusivity, and no explicit representation of deep water formation by plumes in the Southern Ocean (see the appendix).

After 4000 years of integration under modern-day surface forcing, the surface flux of freshwater was diagnosed and held constant during the remainder of the integration. At this time, the salinity at all locations was also increased by a constant multiplicative factor such that the global mean salinity was increased to 35.7, roughly consistent with conditions prior to YD. The circulation was slightly perturbed by this change but soon returned very near to the initial state, with the only significant differcnce bcing the increased mean salinity.

Because of the large oceanic inventory of ${ }^{14} \mathrm{C} \mathrm{com}^{-}$ pared with the corresponding atmospheric inventory, it is desirable to obtain a very steady oceanic ${ }^{14} \mathrm{C}$ field before coupling to the atmosphere. A suitable estimate is obtained by integrating the model for an additional 14,000 years with the atmospheric radiocarbon held at ${ }^{14} C_{0}^{\text {atm }}$ (the subscript 0 denotes steady state values). At the end of this integration, the ratio of decay to uptake for the ocean differs from unity by order $10^{-5}$. The resulting steady state distributions of $\Delta^{14} \mathrm{C}$ in the Pacific and Atlantic basins are shown in Figure 3 (bottom). The most notable differences from previous results occur in the deep Pacific, where the model now shows a well-defined age maximum at middepth, consistent with observations. The new velocity parameterization favors the return of deep water at middepth rather than upwelling to the surface, and this enhances the middepth age maximum consistent with the study of Toggweiler and Samuels [1993].

After steady state ocean conditions are established, the ocean is coupled to interactive atmosphere and biosphere components. To follow the subsequent evolution of radiocarbon in the atmosphere, ${ }^{14} C^{\mathrm{atm}}$, we use the balance 

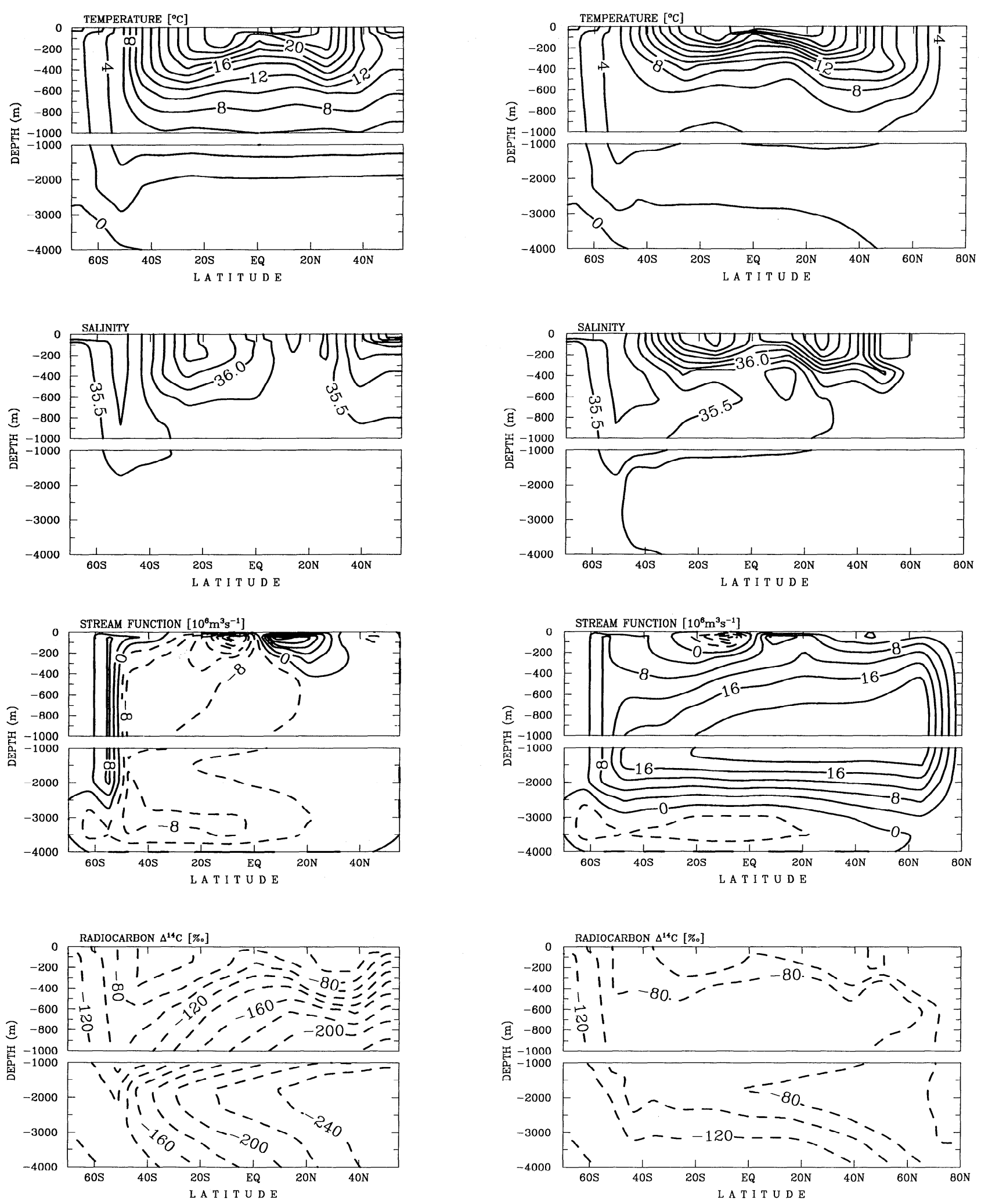

Figure 3. The steady state fields of temperature, salinity (global mean salinity of 35.7, consistent with the value prior to large ice sheet melting), stream function, and $\Delta^{14} \mathrm{C}$ corresponding to the model estimates of present-day conditions for the Pacific (left column) and Atlantic (right column). 


$$
\begin{aligned}
\frac{\partial^{14} C^{\mathrm{atm}}}{\partial t}= & -\lambda^{14} C^{\mathrm{atm}} \\
& +\frac{1}{\rho_{A} h_{A}}\left(F^{\operatorname{cosm}}-F^{A O}-F^{A B}\right)
\end{aligned}
$$

where $\rho_{A}$ and $h_{A}$ surface air density and atmosphere sclae height, respectively, (see the appendix) and $F^{\text {cosm }}$, $F^{A O}$, and $F^{A B}$ are the cosmic production flux and the exchange fluxes from atmosphere to ocean and biosphere, respectively. $F^{\operatorname{cosm}}$ is diagnosed at steady state according to

$$
F^{\mathrm{cosm}}=F_{0}^{A O}+F_{0}^{A B}+\lambda \rho_{A} h_{A} \times{ }^{14} C_{0}^{\mathrm{atm}}
$$

which accounts for our present-day estimates of the decay in the ocean, biosphere, and atmosphere, and is held constant. $F^{\mathrm{AO}}$ and $F^{A B}$ are time dependent due to the transient changes of both air and surface ocean ${ }^{14} \mathrm{C}$ concentrations as well as changes in $p \mathrm{CO}_{2}$ or sea ice cover for some experiments. Since $F^{\text {cosm }}$ is held constant, the global inventory of ${ }^{14} \mathrm{C}$ is conserved. It should be noted that the model variable is ${ }^{14} C^{\text {atm }}$, but since the present version does not include an organic carbon cycle, absolute inventories are not considered and only $\Delta^{14} \mathrm{C}$ changes are investigated. We therefore keep the standard ${ }^{14} \mathrm{C} /{ }^{12} \mathrm{C}$ ratio, $R_{\text {std }}$ constant. In this case, ${ }^{14} C^{\text {atm }}$ and atmospheric $\Delta^{14} \mathrm{C}$ are rclated by a constant linear relationship (see the appendix).

\section{Transient Changes of Ocean Circulation and Atmospheric Radiocarbon}

The particular set of transient experiments that we consider here is based on our previous studies of YD [Wright and Stocker, 1993] and is summarized in Table 1. The steady state is perturbed by freshwater input into the North Atlantic (NA) between $20^{\circ} \mathrm{N}$ and $32.5^{\circ} \mathrm{N}$ at the rates reconstructed by Fairbanks [1989], taking into account some discharge in the Southern Ocean (see caption of Figure 4). The transient evolution of the global THC depends on the strength of the hydrological cycle in the NA. For a fixed hydrological cycle consistent with present-day conditions, deep water formation stops once the melting rate exceeds about $0.2 \mathrm{~Sv}(1 \mathrm{~Sv}=$ $10^{6} \mathrm{~m}^{3} \mathrm{~s}^{-1}$ ) and never recovers.

In a sensitivity study, Wright and Stocker [1993] show that a slight decrease in the strength of the hydrological cycle suffices to produce a response to meltwater input that is qualitatively consistent with the paleoclimatic record. While this gave a reasonable simulation of YD, the required modification of the background hydrological cycle is undesirable. Further, it was not immediately apparent whether or not the required modification of the hydrological cycle was realistic. Here we take an alternative approach that avoids these problems. We still modify the hydrological cycle, as we believe is reasonable, but the initial and final states see present-day conditions, and the physical interpretation of the mod-

\begin{tabular}{|c|c|c|c|c|c|c|}
\hline $\begin{array}{l}\text { Experi- } \\
\text { ment }\end{array}$ & $\Gamma$ & $\begin{array}{l}\text { Cold Phase } \\
\text { Length, years }\end{array}$ & $p \mathrm{CO}_{2}, \mathrm{ppm}$ & $\begin{array}{c}\text { Artificial Ice } \\
\text { at Box \# }\end{array}$ & $\begin{array}{c}\text { Maximuin } \\
\Delta^{14} \mathrm{C}^{\mathrm{atm}}, 0 \% 00\end{array}$ & $\begin{array}{c}\text { Plateau } \\
\text { Length, years }\end{array}$ \\
\hline $\mathrm{C} 1$ & 0.0 & 980 & 280 & - & 35.6 & 43 \\
\hline $\mathrm{C} 2$ & 0.25 & 1530 & 280 & - & 35.6 & 60 \\
\hline $\mathrm{C} 2 \mathrm{a}$ & 0.25 & 1530 & 195 & - & 36.5 & 60 \\
\hline $\mathrm{C} 3$ & 0.5 & 5570 & 280 & - & 36.6 & 77 \\
\hline $\mathrm{T} 1$ & 0.25 & 1530 & $235-280^{\mathrm{a}}$ & - & 32.6 & $65+20$ \\
\hline $\mathrm{T} 2$ & 0.25 & 1530 & $235-280^{b}$ & - & 32.3 & 153 \\
\hline T3 & 0.25 & 1530 & $235-280^{\mathrm{c}}$ & - & 29.7 & 67 \\
\hline I1 & 0.25 & 1530 & 280 & 13 & 36.3 & 62 \\
\hline $\mathrm{I} 2$ & 0.25 & 1530 & 280 & 13,12 & 38.2 & 62 \\
\hline I3 & 0.25 & 1530 & 280 & 13,1 & 43.5 & $7+131$ \\
\hline $\mathrm{I} 4$ & 0.25 & 1530 & 280 & $13,1,2$ & 50.5 & $266^{d}$ \\
\hline I5 & 0.25 & 1530 & 280 & $13,1-3$ & 58.7 & $290^{e}$ \\
\hline
\end{tabular}
ification is both evident and credible.

Table 1. Summary of Experiments

The duration of the cold phase is the time sea ice is present in box 14 , and the length of the age plateau is the time during which $Q_{S}>70 \%$. The time dependence of $p \mathrm{CO}_{2}$ during the glacial-interglacial transition as reconstructed from ice cores is shown in Figure 10, and the prescribed $p \mathrm{CO}_{2}$ is plotted in Figure 11.

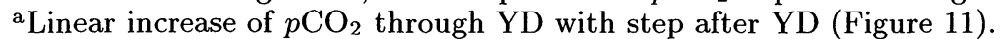

${ }^{\mathrm{b}}$ Linear increase of $p \mathrm{CO}_{2}$ through YD with step at YD (Figure 11).

${ }^{\mathrm{c}}$ Linear increase of $p \mathrm{CO}_{2}$ through YD, no step (Figure 11).

d Two nearby plateaus of 17 and 160 years, appearing as one long plateau of 266 years.

e'Two nearby plateaus of 31 and 182 years, appearing as one long plateau of 290 years (Figure 12d). 


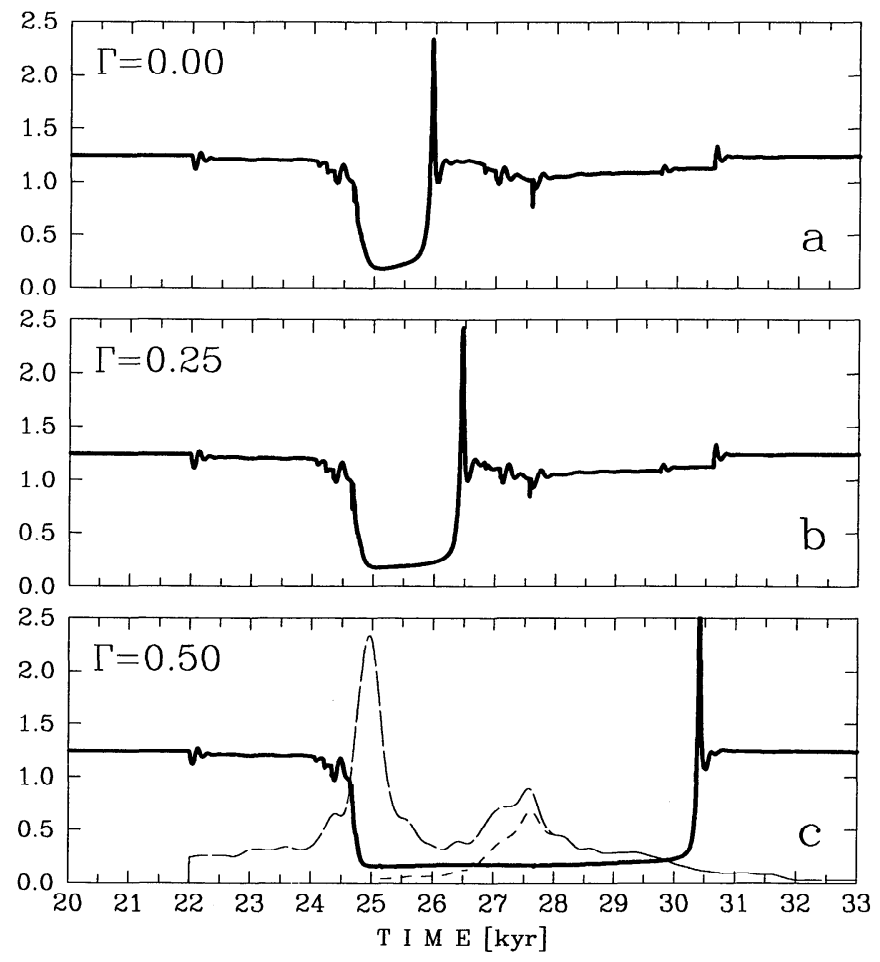

Figure 4. Evolution of the Atlantic meridional heat flux across $32.5^{\circ} \mathrm{N}$ in petawatts $\left(1 \mathrm{PW}=10^{15} \mathrm{~W}\right)$. Shown are cases in which the runoff into the North Atlantic at high latitudes is reduced to (a) 0.00 (experiment C1), (b) 0.25 (experiment C2) and (c) 0.50 (experiment C3) of present-day values as the heat flux is reduced to zero. The meltwater discharges into the North Atlantic and Southern Ocean are indicated by the long- and shortdashed lines, respectively, on a scale of $0-0.5 \mathrm{~Sv}$. The second, weaker meltwater peak appears to be due to a reduction of the ice volume of Antarctica [Peltier, 1994]. This is taken into account by linearly increasing the fraction of Southern Ocean meltwater input from $0 \%$ to $50 \%$ at the expense of the North Atlantic input over the 3000 years following the first meltwater peak.

After the initial spin-up, we calculate the net air-sea freshwater flux, which implicitly includes precipitation $(P)$ minus evaporation $(E)$ plus runoff $(R)$. We determine $E$ following Stocker et al. [1992] and $R$ based on estimates of Baumgartner and Reichel [1975]. $P$ is then given as the residual. The values of $P-E$ are fixed in each model grid cell for the subsequent integrations. Thus changes in $E$ can affect the air-sea heat exchange but not the net exchange of water. The only changes in water fluxes seen by the ocean in this model are those associated with runoff.

We argue that during a cold event, the hydrological cycle in the North Atlantic region is reduced [Alley et al., 1993]. This is taken into account by reducing the $R$ in the Atlantic north of $40^{\circ} \mathrm{N}$ during this period by a fraction that depends on the meridional heat flux in the North Atlantic. Let $R_{0}^{\mathrm{NA}}$ be the estimated present-day runoff into the NA [from Baumgartner and Reichel, 1975 ] and let $F_{0}^{\mathrm{NA}}$ be the steady state heat flux of the North Atlantic across $20^{\circ} \mathrm{N}$. Temporal variations of the runoff into the NA, $R^{\mathrm{NA}}$, are determined by

$$
R^{\mathrm{NA}}=\left\{\begin{array}{l}
\Gamma R_{0}^{\mathrm{NA}} \\
{\left[\left(\Gamma F_{0}^{\mathrm{NA}}+(1-\Gamma) F^{\mathrm{NA}}\right) / F_{0}^{\mathrm{NA}}\right] R_{0}^{\mathrm{NA}}} \\
R_{0}^{\mathrm{NA}}
\end{array}\right.
$$

where $F^{\mathrm{NA}}$ is the instantaneous meridional heat flux at $20^{\circ} \mathrm{N}$ in the Atlantic and $\Gamma$ is an adjustable parameter, and the three cases in equation (7) refer to $F^{\mathrm{NA}}<0$, $0 \leq F^{\mathrm{NA}} \leq F_{0}^{\mathrm{NA}}$, and $F^{\mathrm{NA}}>F_{0}^{\mathrm{NA}}$, respectively. Any runoff that is subtracted from the NA is redistributed uniformly over the remainder of the global ocean. This compensating water flux does not significantly affect the stability of the THC. It is included to insure that our background water budget remains balanced so that the Fairbanks [1989] meltwater curve corresponds to the net addition of water to the ocean. For $\Gamma=0$, runoff into the NA is completely eliminated north of $40^{\circ} \mathrm{N}$ if the heat flux across $20^{\circ} \mathrm{N}$ is zero or negative, and for $\Gamma=1$, the runoff is fixed at the present-day estimate, independent of the heat flux.

\section{Behavior of the Circulation}

Figure 4 shows the evolution of the NA heat flux during meltwater input for three values of $\Gamma$, Figure 5 gives the evolution of several model quantities for the particular case of $\Gamma=0.25$, and Figure 6 displays the Atlantic stream functions and $\Delta^{14} \mathrm{C}$ near the end of the collapsed circulation state. The meltwater inputs to both the NA and the Southern Ocean are shown on the lower panel of Figure 4, and just the northern hemisphere input is given in Figure 5, on a scale of 0 to $0.5 \mathrm{~Sv}$. Results are not substantially changed if all of the meltwater enters the ocean in the northern hemisphere. Note that the heat flux is controlled by the strength of the overturning circulation, so plots of these two quantities look very similar (compare Figure $4 \mathrm{~b}$ and Figure 5b).

In spite of several model modifications, our results are quite similar to those of Wright and Stocker [1993]. For all values of $\Gamma$, the Atlantic overturning circulation "collapses" when the meltwater input exceeds about 0.2 Sv. If runoff into the NA is not reduced, the circulation never recovers. On the other hand, if the meltwater input is reduced by about $0.15 \mathrm{~Sv}(\Gamma=0.25$, Figure $5 \mathrm{~g})$, then the overturning abruptly recovers to near its initial state after about 1500 years, in reasonable agreement with the timing indicated by observations. It should be noted that the exact value of $\Gamma$ required to obtain a realistic timescalc for the YD event depends on uncertain details of the meltwater curve. For example, if the meltwater input to the NA is reduced to zero at all times when the melting rate according to Fairbanks [1989] drops below $0.1 \mathrm{~Sv}$, then the results correspond- 

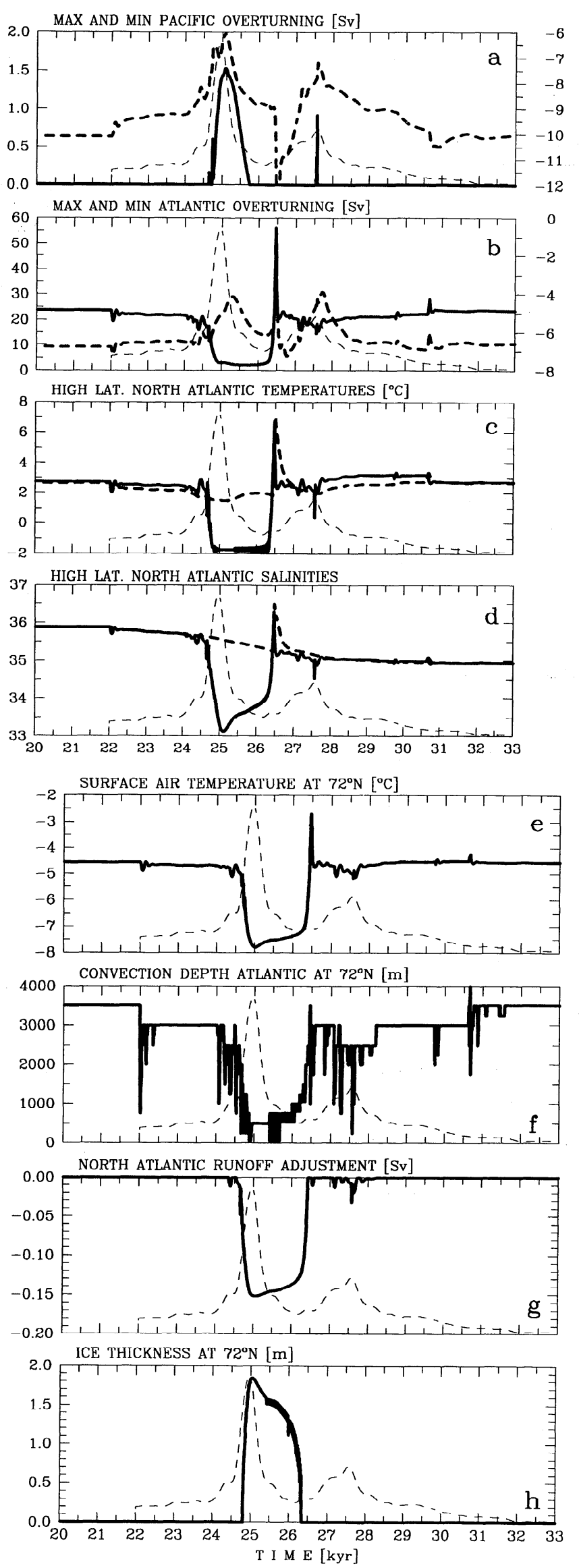

ing to $\Gamma=0.5$ (not shown) are very similar to the results with $\Gamma=0.25$ shown here. The results of Edwards et al. [1993] indicate that such changes are well within the uncertainty in the observational estimates.

The primary, dynamically important influence of meltwater input is that the surface salinity of the NA is reduced. Because of this, the water column reaches a point where surface cooling is not sufficient to cause deep convection, and the cold surface waters are effectively isolated from the deep ocean. The density of the high-latitude NA is decreased at all depths, owing to reduced salinity near the surface and to increased temperature at depth. Consequently, the NA overturning circulation weakens and the meridional heat flux is strongly reduced (Figure 4b). Cooling of the surface waters results in the formation of sea ice (Figure $5 \mathrm{~h}$ ), but this does not appear to play a crucial role in the model evolution, since removing sea ice altogether does little other than cause unrealistically low high-latitude ocean surface tcmperatures (perhaps this lack of sensitivity would be modified if seasonal cycles were included). However, sea ice strongly influences the air-sea exchange of ${ }^{14} \mathrm{C}$ and therefore the characteristics of the radiocarbon clock during YD. The occurrence of sea ice is also a convenient indicator for the length of YD (Figure $5 \mathrm{~h}$ ); we will use the time when sea ice is present in the northernmost cell of the Atlantic (north of $65^{\circ} \mathrm{N}$ ) as a quantitative measure of the duration of $\mathrm{YD}$ in this model.

Surface air temperatures in the North Atlantic region cool substantially during YD (Figure 5e), and reduced runoff into the NA is a presumed consequence of this cooling. The reduced runoff plays a critical role since it causes a gradual increase in the high-latitude surface salinity. Eventually (after about 1500 years for $\Gamma=0.25$ ), the surface salinity is increased to the point that the stabilizing effect of the salinity stratification is no longer adequate to compensate for the destabilizing effect of the temperature stratification. At this time, the surface layer mixes with the water below, and both the surface temperature and salinity are increased. Heat loss to the atmosphere quickly reduces the temper-

Figure 5. Evolution of selected quantities for experiment C2 (Figure 4b): (a) maximum (solid line) and minimum (dashed line) of the Pacific stream function below $1000 \mathrm{~m}$; (b) maximum (solid) and minimum (dashed line) of the Atlantic stream function below 1000 $\mathrm{m}$; (c) shallow (solid line) and deep (dashed line) temperature in the northernmost cell of the Atlantic; (d) shallow (solid line) and deep (dashed line) salinity in the northernmost cell of the Atlantic; (e) surface air temperature over the northernmost cell; (f) convection depth in the northernmost cell; $(\mathrm{g})$ fraction of initial runoff north of $40^{\circ} \mathrm{N}$ in the Atlantic basin; and (h) sea ice thickness in the northernmost cell. 

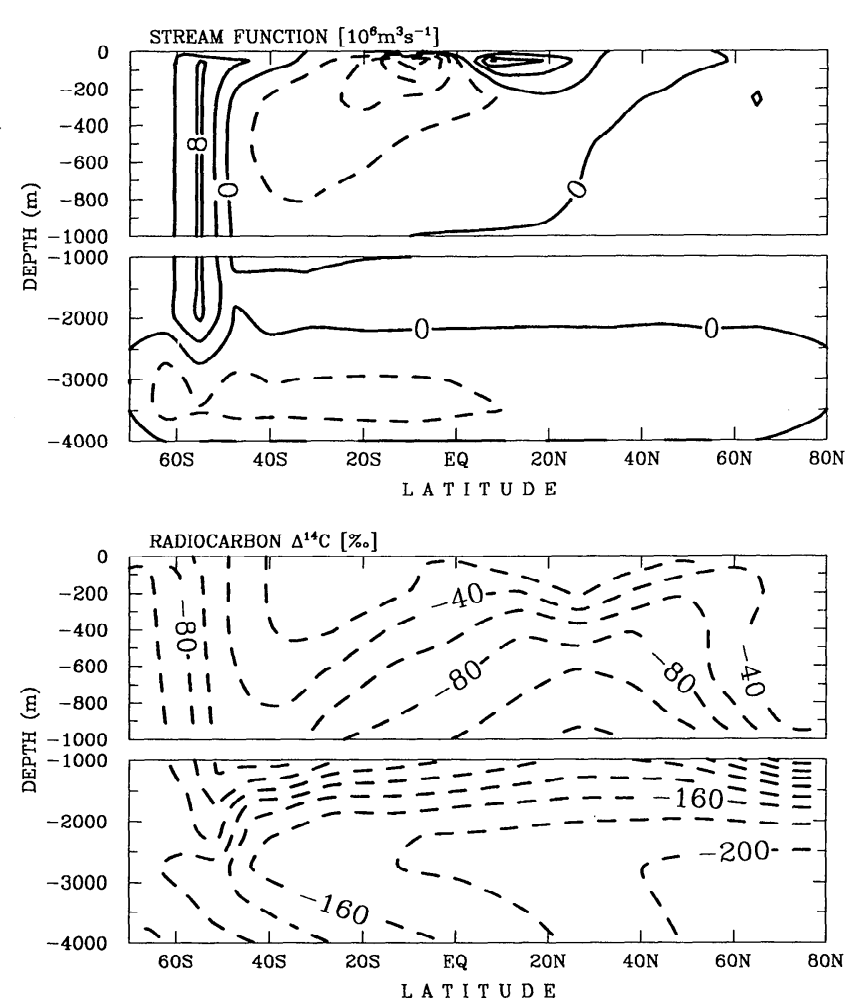

Figure 6. Stream function and $\Delta^{14} \mathrm{C}$ in the Atlantic during the Younger Dryas event, a few hundred years before the circulation recovers (year 26,000).

ature of the surface layer, which leaves an even more unstable situation because of the increased surface salinity. This positive feedback efficiently cools the water column, and the Atlantic branch of the conveyor belt is reinitiated as a consequence. It is this local, convective feedback that is responsible for the very rapid termination of YD in our model.

It has been argued that the atmospheric heat capacity is influential in determining the stability of the THC because decreasing sea surface temperatures, which accompany a THC collapse, would cause lower surface air temperatures and so maintain the ocean-to-atmosphere heat fluxes [Zhang et al., 1993; Rahmstorf, 1994]. However, this has not been tested using realistic amplitudes of glacial freshwater flux perturbations as considered here. We have rerun these experiments with $h_{A}=832$ $\mathrm{m}$ and $h_{A}=416 \mathrm{~m}$ with no significant differences to our results. In none of the cases was a stabilization of the THC observed.

It is important to discuss how the transient behavior of the present model compares with models that include more complete dynamics. Mikolajewicz and Maier-Reimer [1994] investigate the transient evolution of their OGCM to increasing freshwater flux perturbations into the North Atlantic. The meltwater causes an abrupt and complete collapse of the THC in the Atlantic after an initial gradual decrease. The present results (Figure 4 and Figure 6) are consistent with both features. A switch-on of the THC was achieved by introducing negative meltwater fluxes. After some smaller initial changes, the circulation was reestablished very rapidly, showing "overshoots" of heat fluxes. This OGCM was recently coupled to an energy balance model of the atmosphere with very similar transient behavior (U. Mikolajewicz, submitted manuscript, 1996). The model also shows a significant warming in the southern hemisphere (up to $6^{\circ} \mathrm{C}$ ) during YD. We find again remarkably similar transient behavior in the zonally averaged, coupled model.

Manabe and Stouffer [1995] have applied perturbation fluxes of very short duration (10 years) to their A/OGCM and also find rapid reduction and, after the perturbation is switched off, rapid reinitiation of the Atlantic THC. A full collapse was not observed, but the model would most probably settle to such a circulation state if the perturbation had been applied over a longer period [Manabe and Stouffer, 1993]. A full collapse of the Atlantic circulation was simulated in the A/OGCM of A. Schiller (The stability of the thermohaline circulation in a coupled ocean-atmosphere general circulation model, submitted to Climate Dynamics, 1996). They also identified a new stabilizing feedback mechanism associated with the formation of a cyclonic circulation anomaly in the northern North Atlantic which leads to a destabilization of the collapsed state in their model. This mechanism may be important in that it could result in a THC recovery with a reduced modification of the hydrological cycle.

In summary, the simplified dynamics do not appear to distort the transient behavior of the ocean in any way significant for the present experiments. However, the changes in the hydrological cycle that are required to reinitiate the THC may be overestimated by our model. It is common to all models that the freshwater pulse applied in the North Atlantic causes a collapse of the THC without significant delay. The latest sea level reconstruction indicates that the first meltwater peak occured about 1000 years prior to the beginning of YD [Bard et al., 1996]. Comparison with the ice core $\delta^{18} \mathrm{O}$ record suggests that this triggered a series of cold spells with growing amplitude that eventually led to the YD. Before this delay can be successfully modeled, however, the location of the meltwater discharge needs to be better established. It may well be that part of the first meltwater peak occurred around Antarctica [Clark et al., 1996] and only a later portion was actually discharged into the North Atlantic.

\section{Variability of $\Delta^{14} C^{\text {atm }}$ in the Model}

We now consider the effect of transient changes of the ocean ventilation on the major radiocarbon reservoirs. For the standard experiment, C2 (Table 1), $\Delta{ }^{14} \mathrm{C}$ 
increases by about $35 \%$ in the atmosphere, the biosphere, and the upper ocean, as a result of the reduced ventilation which causes a substantial decrease of $\Delta^{14} \mathrm{C}$ in the deep ocean (Figure 7a). This is in good agreement with the results of Goslar et al. [1995] but a factor of 2 to 3 higher than the values found by U. Mikolajewicz (submitted manuscript, 1996). The reason for this discrepancy might lie in the fact that convection in the Southern Ocean increases by about $40 \%$ in their model during the cold event.

The increase of $\Delta^{14} \mathrm{C}$ starts as soon as the Atlantic overturning slows down, but the major changes occur when deep water formation in the North Atlantic collapses (at about model year 24,600). It is important
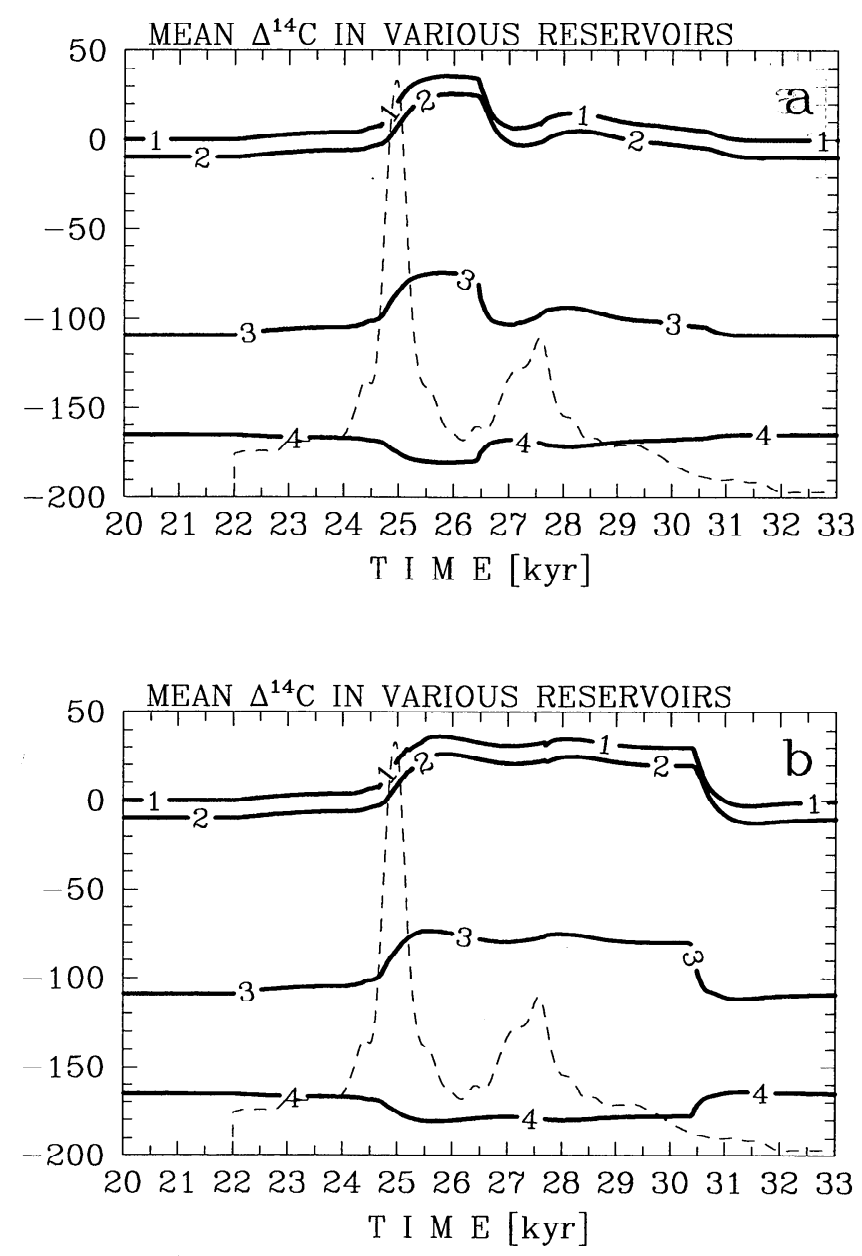

Figure 7. (a) Evolution of mean $\Delta^{14} \mathrm{C}$ in the major reservoirs for the standard experiment C2 (Figure $4 \mathrm{~b})$. The radiocarbon inventory increases in atmosphere (curve 1), biosphere (curve 2), and the upper $1000 \mathrm{~m}$ of the ocean (curve 3), while it decreases in the deep ocean (curve 4) due to reduced ventilation. (b) Evolution of mean $\Delta^{14} \mathrm{C}$ in the major reservoirs for experiment C3 (Figure 4c), where the thermohaline circulation stays collapsed for more than 5500 years. The radiocarbon inventory increase in the atmosphere is not significantly larger than in Figure 7a.

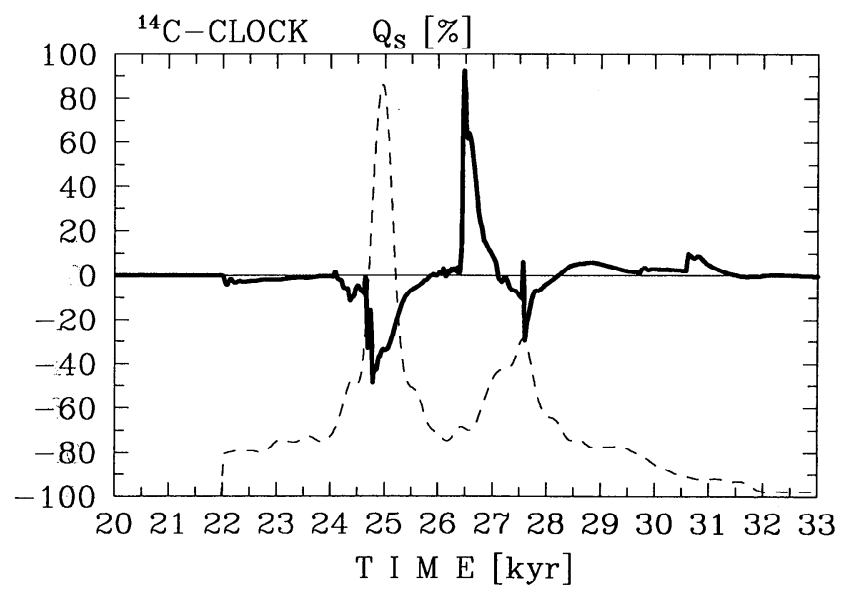

Figure 8. Evolution of the slowdown of the radiocarbon clock, $Q_{S}$, for experiment $\mathrm{C} 2$. The rise of ${ }^{14} C^{\mathrm{atm}}$ causes an "acceleration" of the clock, while reinitiation of the ventilation produces a slowdown. The meltwater discharge into the North Atlantic is shown by the dashed line on a scalc of $0-0.5 \mathrm{~Sv}$.

to note that a major part of the deep ocean $\Delta^{14} \mathrm{C}$ decrease is compensated for by the surface ocean and the biosphere, which will have implications for the surface reservoir ages and the top-to-bottom age differences at various locations of the ocean. A much longer shutdown of the THC (5000 years, Figure 4c) does not result in significantly higher $\Delta^{14} \mathrm{C}$ values in the atmosphere (Figure $7 \mathrm{~b}$ ). This indicates that after roughly 1000 years, the remaining ventilation by Antarctic Bottom Water (AABW) and vertical diffusion balance the natural decay of the reduced ${ }^{14} \mathrm{C}$ inventory in the deep ocean.

Changing oceanic ${ }^{14} \mathrm{C}$ uptake influences the "accuracy" of the radiocarbon clock. Figure 8 shows $Q_{S}$, the percentage slowdown of the radiocarbon clock according to equation (4) for the base experiment, C2. Intermittent convection causes some very abrupt short-lived variations, but the basic picture is quite simple. When the meltwater input exceeds about $0.2 \mathrm{~Sv}$, the formation of deep water in the NA is terminated, causing an increase of $\Delta^{14} \mathrm{C}$ which makes ages appear younger. For the particular case shown in Figure 8, the clock speeds up by 30 to $40 \%$ over a period of a few hundred years. The formation of deepwater in the NA is not reinitiated until just before year 26,470 , but the radiocarbon clock is already running slightly slow at least 500 years earlier. This is a consequence of the continued flushing of the deep basins by AABW. When the Atlantic overturning circulation first collapses, the northward flow of AABW (represented by the minimum overturning transport) is slightly reduced in both the Atlantic and Pacific basins (see Figures 5a and 5b). These changes contribute to the increased speed of the clock during this period. The slightly increased strength of the overturning in the North Pacific acts in the opposite direction but is too small to counter the speedup associated 
with the other changes. During the next few hundred years, higher ${ }^{14} C^{\text {atm }}$ causes an increase in radiocarbon in the entire surface ocean through gas exchange. Owing to continuing deep water formation in the Southern Ocean, AABW gradually brings more radiocarbon into all deep basins except the Atlantic, where the loss of ventilation associated with North Atlantic Deep Water formation is not completely compensated, even though the penetration of AABW into the Atlantic basin is increased. The clock starts to slow down well before deep water formation in the $\mathrm{NA}$ is reinitiated, emphasizing the importance of the Southern Ocean in determining the ocean inventory, and hence ${ }^{11} C^{\text {atm }}$, during YD.

The overturning in the NA is reinitiated very abruptly near year 26,470 (sea ice has disappeared completely by year 26,330 ). The initial input of surface water associated with the positive convection feedback process discussed earlier causes the clock to stop for a brief period. Subsequently, the flushing of the deep Atlantic by the advection of new NADW into the abyssal ocean is sufficient to slow the clock by over $70 \%$ for about 60 years.

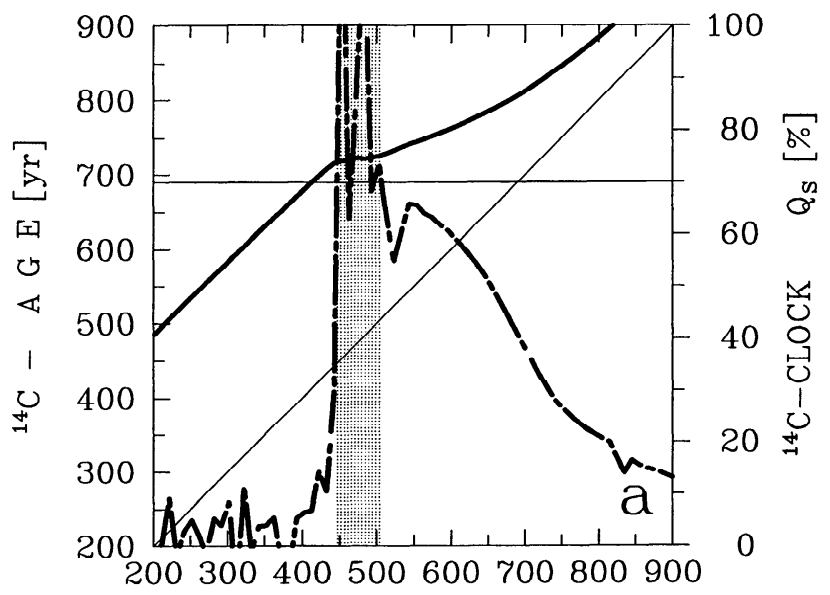

T I M E [yr]

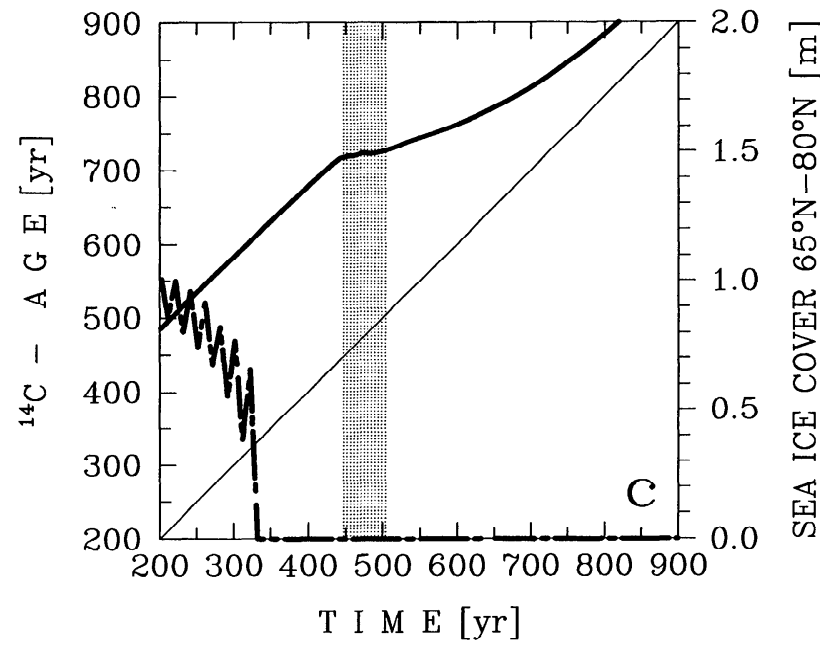

The definition of an age plateau is somewhat arbitrary. Inspection of Figure 9a suggests that $Q_{S}>70 \%$ is a sensible criterion consistent with an identification of the plateau solely on the basis of the age-age relation. Using this criterion, the age plateau has a length of about 60 years and occurs at the time of the fastest rates of climate change in the atmosphere (Figure $9 \mathrm{~b}$ ) but about 140 years after the disappcarance of sea ice north of $65^{\circ} \mathrm{N}$ (Figure 9c). We note that the duration of the modeled plateau is considerably shorter than observed (Figure 1).

After the Atlantic overturning has recovered, the only significant perturbation of the radiocarbon clock is the increase in speed near year 27,500. This increase is associated with the second meltwater pulse and is similar to that due to the first pulse. However, the second pulse does not cause a collapse of the NA circulation, so the effect is weaker. Also, the subsequent slowing of the radiocarbon clock as the system adjusts to its final equilibrium is gradual, extending over a couple of thousand years rather than occuring abruptly in response to a rapid flushing event as occurs at the end of YD.

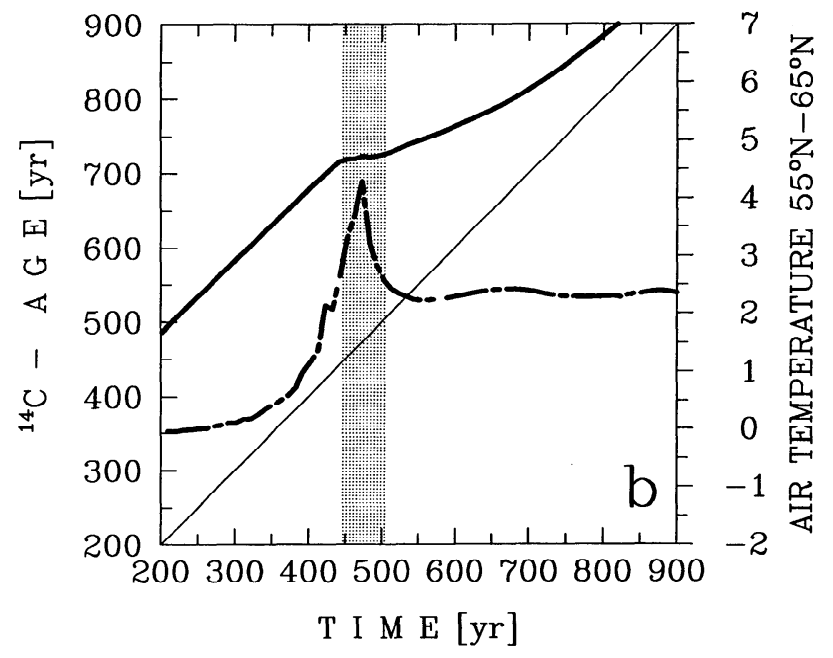

Figure 9. (a) Detailed view of the age plateau (solid line) and $Q_{S}$ (dash-dotted line) at the termination of YD of experiment C2. Using the $Q_{S}>70 \%$ criterion, the plateau lasts for about 60 years (shaded area). (b) The plateau occurs at the location of most rapid change in surface air temperature. (c) The plateau occurs about 150 years after the complete disappearence of sea ice north of $65^{\circ} \mathrm{N}$ in the Atlantic. Note that 26,000 years have been subtracted from the timescale and that the time axis is reversed in comparison to Figure 1. 


\section{Duration of the Age Plateau}

The strength and duration of the age plateau due to changes in ocean circulation depends on (1), the depletion of the oceanic radiocarbon inventory during the period of reduced circulation, (2) the efficiency of the reestablishment of NADW formation, and (3) the evolution of the gas exchange rate (including sea ice cover) during the climate transition. During the time of the collapse of the THC in the North Atlantic, the deep ocean is still weakly ventilated via the Southern Ocean (Figure 6) and vertical diffusion. As long as sea ice is not modifed during YD, a natural limit of the depletion of radiocarbon in the deep ocean exists in this model, with the result that $\Delta^{14} \mathrm{C}$ does not exceed about $35 \%$ (Table 1).

Experiments show that the characteristics of the termination are relatively insensitive to the length of the preceding cold period. Even if YD lasts for over 5500 years (experiment C3), this causes only a somewhat longer-lasting slowdown of the clock for 150-300 years after the termination but one too weak to be recognized as an age plateau. Also, experiment $\mathrm{C} 2 \mathrm{a}$, which differs from $\mathrm{C} 2$ only through the use of a reduced gas exchange rate based on $p=195 \mathrm{ppm}$ throughout the experiment instead of $p=280 \mathrm{ppm}$, shows very little difference in the duration of the age plateau (Table 1 ).

Another mechanism that could influcnce the length of a plateau is associated with varying gas exchange rates (perhaps due to transient changes of $p \mathrm{CO}_{2}$; see equation (A5)). Although we will change $p \mathrm{CO}_{2}$ in the model, the ${ }^{12} \mathrm{C}$ inventory will not be changed, as we are only interested in the effect of changes of the gas exchange rate on the radiocarbon clock. Effects related to ${ }^{12} \mathrm{C}$ inventory changes cannot be studied with the present model due to the lack of a marine carbon cycle model component. Figure 10 shows the evolution of $\mathrm{CH}_{4}$ and $\mathrm{CO}_{2}$ for the last 20,000 years as reconstructed from polar ice cores. 'The timescale of the Byrd core from Antarctica, on which $\mathrm{CO}_{2}$ is measured, is connected to the timescale of the GRIP (Greenland Ice Sheet Project) core via methane measurements on both cores. Distinctly reduced methane concentrations during the period from about $12,700 \mathrm{yr}$ B.P. to about 11,500 yr B.P. allows the location of YD in the $\Lambda$ ntarctic core which cannot be clearly recognized in other variables. From the warm Bølling/Allerød through YD to the warm Preboreal, there is a significant increase of $p \mathrm{CO}_{2}$ from 235 ppm to $280 \mathrm{ppm}$, and hence the gas exchange rate increases by about $20 \%$. Moreover, shortly after the start of the $\mathrm{CH}_{4}$ increase which marks the YD termination, there is an almost step increase in $p \mathrm{CO}_{2}$ from $260 \mathrm{ppm}$ to $280 \mathrm{ppm}$. The secular as well as the step increase contribute additionally to an enhanced uptake of ${ }^{14} \mathrm{C}$ into the ocean at the termination; this tends to increase the duration of the plateau.

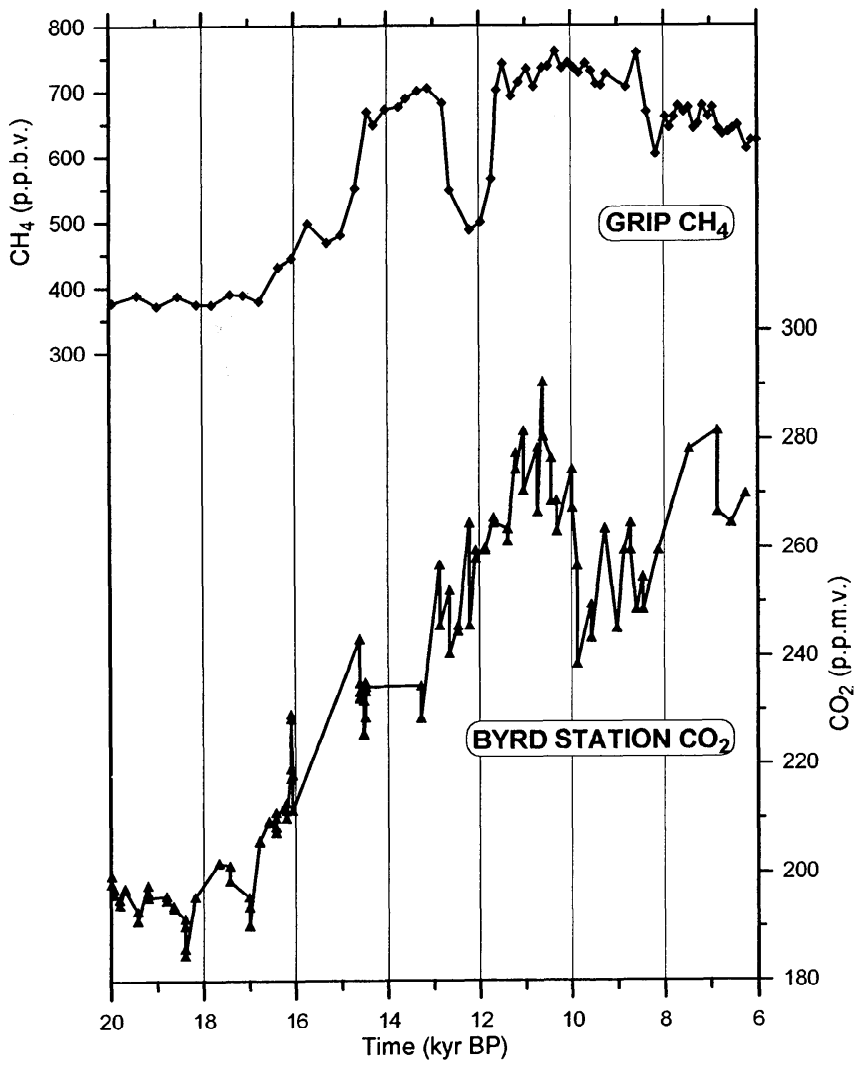

Figure 10. Evolution of $p \mathrm{CO}_{2}$ and $\mathrm{CH}_{4}$ during the last 20,000 years as reconstructed from measurements of air enclosed in bubbles in the Byrd ice core (data from Neftel et al. [1988] and Staffelbach et al. [1991] with the new timescale by Hammer et al. [1994]) and in the GRIP ice core (data from Chappellaz et al. [1993] and Blunier et al. [1995]). The YD event falls into a time of increase of $p \mathrm{CO}_{2}$ from 235 ppm to 280 ppm within about 2000 years. This implies an increase of the gas exchange rate by about $20 \%$ according to equation (A5).

We have run several experiments, summarized in Table 1 , each of which has a different prescribed evolution of the gas exchange rate $g$ but transient changes of the circulation identical to experiment $\mathrm{C} 2$. The value of $g$ is calculated according to equation (A5) by approximating the $p \mathrm{CO}_{2}$ record by linear segments, as shown in Figure 11 (time axis consistent with model experiments). For $\mathrm{T} 1$, two short plateaus of 60 and 20 years, separated by 300 years, are present (Figure 12a), whereas in $\mathrm{T} 2 \mathrm{a}$ coherent age plateau of over 150 years is formed (Figure $12 \mathrm{~b})$. It is evident that the exact location of the abrupt increase of gas exchange influences whether or not an extended plateau is formed. Finally, experiment T3 demonstratcs that a rapid increasc of $p \mathrm{CO}_{2}$ is necessary to extend the plateau and a simple linear increase is not sufficient.

'The next set of experiments investigates the dependence of the plateau duration on ice cover. The present 


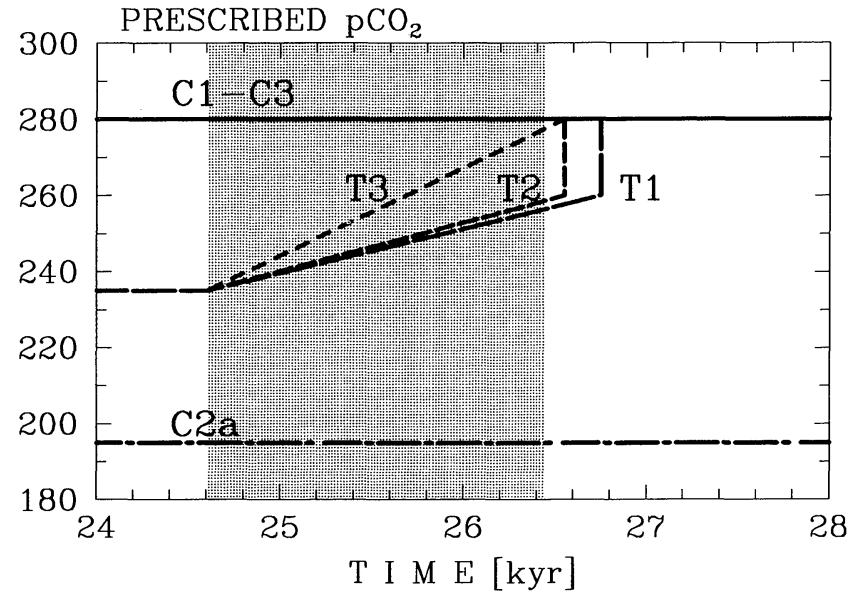

Figure 11. Prescribed $p \mathrm{CO}_{2}$ for experiments $\mathrm{T} 1-\mathrm{T} 3$. The cold phase is shaded. model contains a simple thermodynamic ice component. For all experiments of Table 1 the only location with permanent sea ice during YD is grid box 14 (Atlantic north of $60^{\circ} \mathrm{N}$; see Figure 2). Thus, while our sea ice model gives qualitatively reasonable results and serves to prevent unrealistically low surface temperatures, it is likely that it underestimates the sea ice extent during YD. Rather than changing the transient behavior by modifying various model parameters, we choose experiment $\mathrm{C} 2$ as our base configuration and prescribe "artificial" sea ice at various locations during YD (defined as the time when sea ice is present in box 14). The only effect of this artificial sea ice is to reduce the airsea exchange of radiocarbon by $95 \%$ in the respective surface box.

In experiment I1, box 13 was prescribed to be covered with sea ice during YD. The effect on maximum
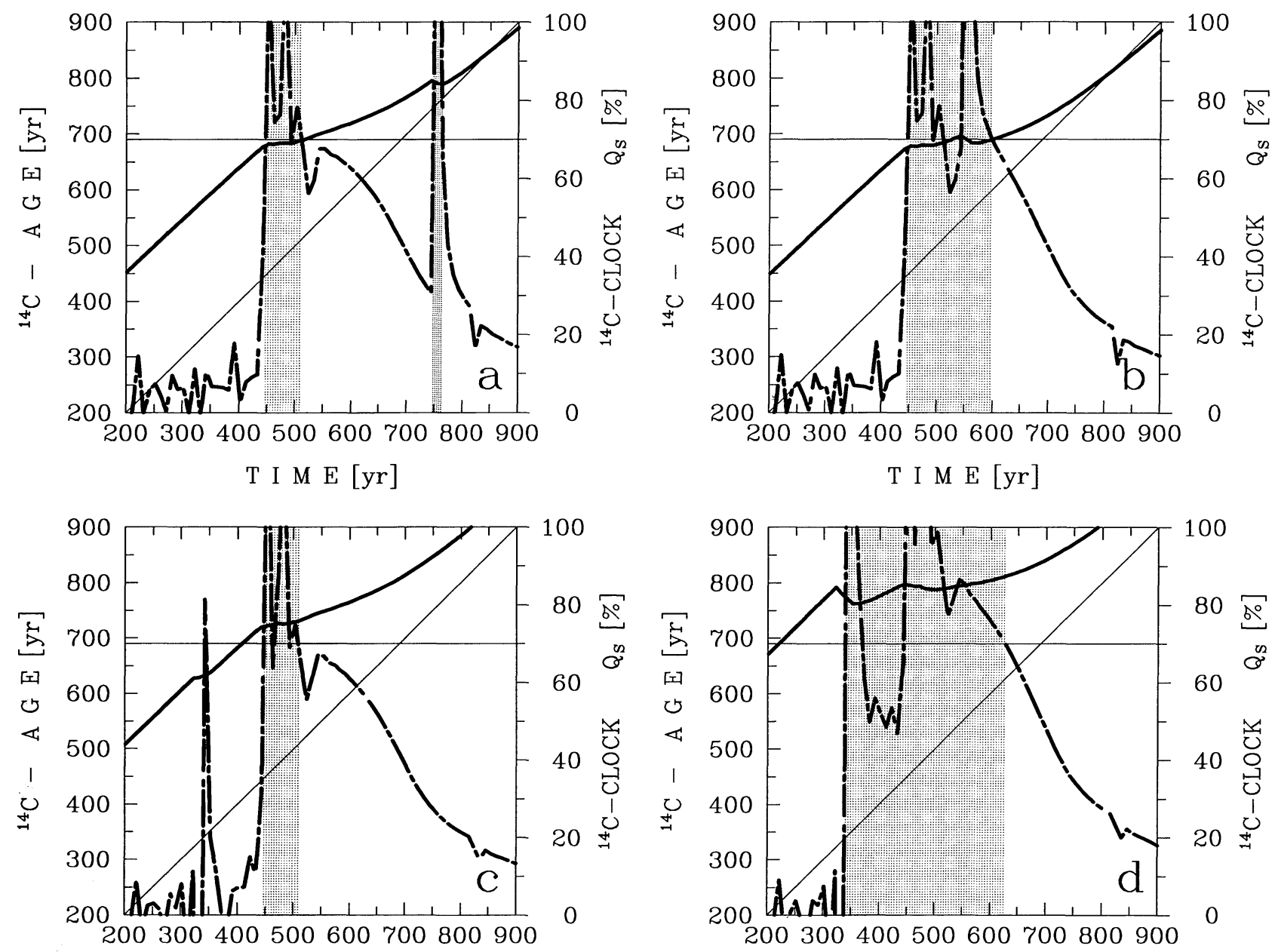

T I M E [yr]

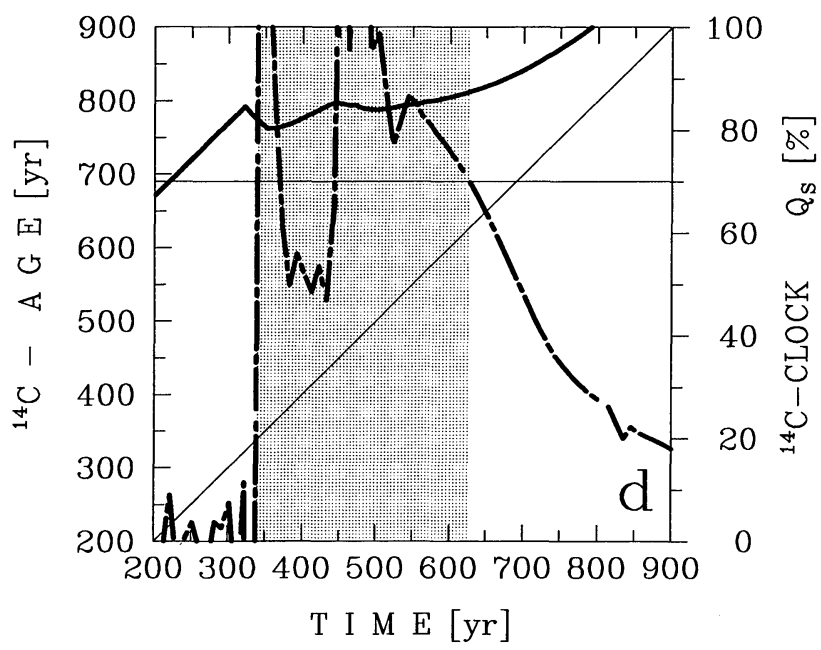

Figure 12. Age plateau (shaded area) and slowdown of the radiocarbon clock (dash-dotted line) for a prescribed evolution of the gas exchange coefficient (Figure 12a, experiment T1; Figure 12b, experiment T2) or a prescribed "artificial" sea ice cover (Figure 12c, experiment I2; Figure 12d, experiment I5). Note that 26,000 years have been subtracted from the timescale and that the time axis is reversed in comparison to Figure 1. 
atmospheric $\Delta^{14} \mathrm{C}$ and plateau length is negligible, but surface reservoir ages are significantly increased (see below). For experiment I2, sea ice is prescribed down to $45^{\circ} \mathrm{N}$ in both the Pacific and Atlantic. The length of the plateau is increased only slightly, and a very short precursor to the plateau occurs (Figure 12c). This is caused by the increased gas exchange due to the rapid removal of sea ice cover, while the main plateau is attributed to the switch-on of deep water formation.

There is evidence that YD was a global event and that the southern hemisphere might also have experienced a cooling [Denton and Hendy, 1994], although this has been disputed [Mabin, 1996]. At present, the mechanisms responsible for a possible transmission of the climate signal to the south or the generation of a global signal independent of the Atlantic region can only be speculated about. All climate models, with which YDtype experiments have been performed up to now, show either no significant temperature changes [Manabe and Stouffer, 1995] or a warming (U. Mikolajewicz, submitted manuscript, 1996) in the southern hemisphere. In the present model, sea surface temperature (SST) at $65^{\circ} \mathrm{S}$ warms by about $2^{\circ} \mathrm{C}$ during YD, consistent with the latter study. While the models exclude any increase of sea ice cover in the southern hemisphere, the observations apparently suggest otherwise. Here we estimate the influence on ${ }^{14} C^{\text {atm }}$ and the duration of the subsequent age plateau of a gradual closure of the Southern Ocean sea surface by an ice cover. However, it must be kept in mind that such experiments are inconsistent with the Southern Ocean warming simulated by our model.

As shown in Table 1 (experiments I3-I5), closure of the Southern Ocean reduces the amount of ${ }^{14} \mathrm{C}$ that is sequestered by the ocean and hence increases the maximum ${ }^{14} C^{\text {atm }}$ during YD. The larger reduction in the ocean inventory also has a strong influencc on the length of the subsequent age plateaus. The sudden removal of the southern ice cover (south of $48^{\circ} \mathrm{S}$ at year 26,330 ) contributes to increased uptake of ${ }^{14} \mathrm{C}$ and produces a very strong first plateau (Figure 12d). $Q_{S}$ then falls below $70 \%$ for a few decades until increased convection in the North Atlantic produces the second longer plateau not unlike Figure 1. The entire evolution may be interpreted as one single, longer plateau of about 300 years duration.

It is clear from these experiments that changing sea ice cover, especially in the large areas of the Southern Ocean, can have a profound impact on ${ }^{14} C^{\text {atm }}$. There are still inconsistencies regarding the mechanisms of YD. Long plateaus and indications of climate change in the southern hemisphere tell us that YD might have been a global event, probably enhanced in the North Atlantic region. Models, on the other hand, still simulate cooling mostly around the North Atlantic and even warming in the southern hemisphere.

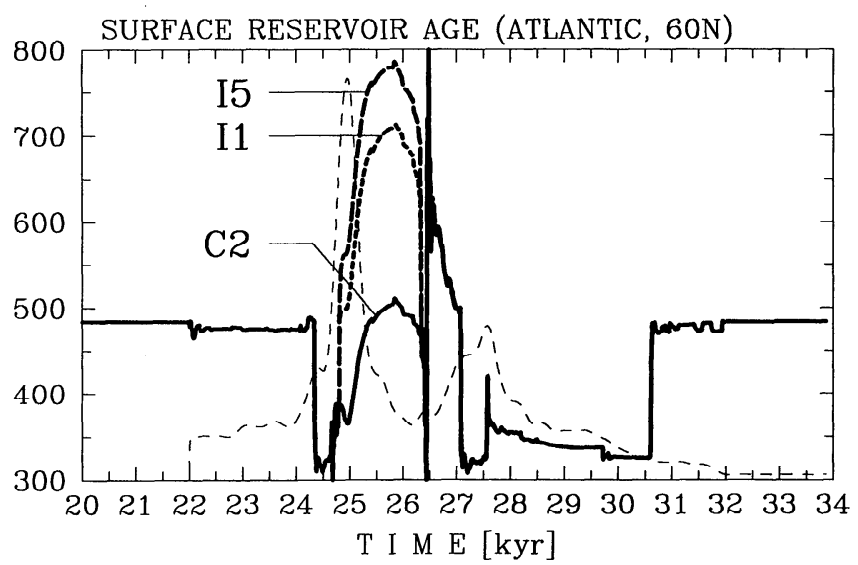

Figure 13. Evolution of the surface reservoir age in the Atlantic at $60^{\circ} \mathrm{N}$ for a constant gas exchange rate (experiment $\mathrm{C} 2$ ). If sea ice is present, the age increases by 200-300 years (experiments I1 and I5), in good agreement with observational estimates [Bard et al., 1994].

\section{Surface Reservoir Ages and Top-to-Bottom Age Differences}

Bard et al. [1994] estimate that the surface reservoir age in the North Atlantic was about $200-300$ years higher during YD due to reduced advection and the presence of sea ice. Our results show that the surface reservoir age is primarily determined by gas exchange and convection (Figure 13). A few hundred years prior to $\mathrm{YD}$, the age drops abruptly due to the shallowing of convection and the reduced upward mixing of older waters. Once the circulation is shut down after the onset of YD, the surface equilibrates again with the atmosphere to an age of about 500 years. At the particular location (grid box 13), no ice is being formed in experiment $\mathrm{C} 2$, which is the reason why there is practically no age increase during YD relative to the time before. A few hundred years before termination, the age decreases again due to shallower convection during that phase. Reinitiation of deep convection mixes up old Atlantic deep waters, increasing surface reservoir age considerably and allowing the rapid uptake of ${ }^{14} C^{\mathrm{atm}}$. The model then settles to lower reservoir ages for a few thousand years before full rcestablishment of convection to previous levels. It is interesting to note that the increase of reservoir age by about 150 years at $t=30,800$ years is associated with increased convection in the northernmost cell of the NA (Figure 5f) and a slight decrease in surface ocean temperature in the same region. It is almost unnoticed in the climatic variables such as surface air temperature (Figure 5e).

Local icc cover increases the surface reservoir ages considerably: For experiments I1-I5, gas exchange in box 13 is reduced by $95 \%$ during $\mathrm{YD}$. This increases the reservoir ages by 230-300 years, a value that is in good agreement with the estimates of Bard et al. [1994]. The 
larger increase of $\mathrm{I} 5$ is caused by higher ${ }^{14} C^{\text {atm }}$ during YD (see Table 1).

A final indicator is the top-to-bottom age difference at various locations of the ocean. Figure 14 shows time series of the age difference for three typical locations for experiment T2. As one may anticipate from Figure 6 , the deep ocean age increases in the Atlantic because the supply of young deep water is interrupted. Higher ${ }^{14} C^{\text {atm }}$, and hence surface concentrations add to the increase of the age difference to give a total change of about 1500 years. In the Pacific (Figure 14b), the age difference increases by about 550 years, mainly due to the latter effect, and changes in the deep ocean are of secondary importance except for the second increase at $t=28,500$ years.
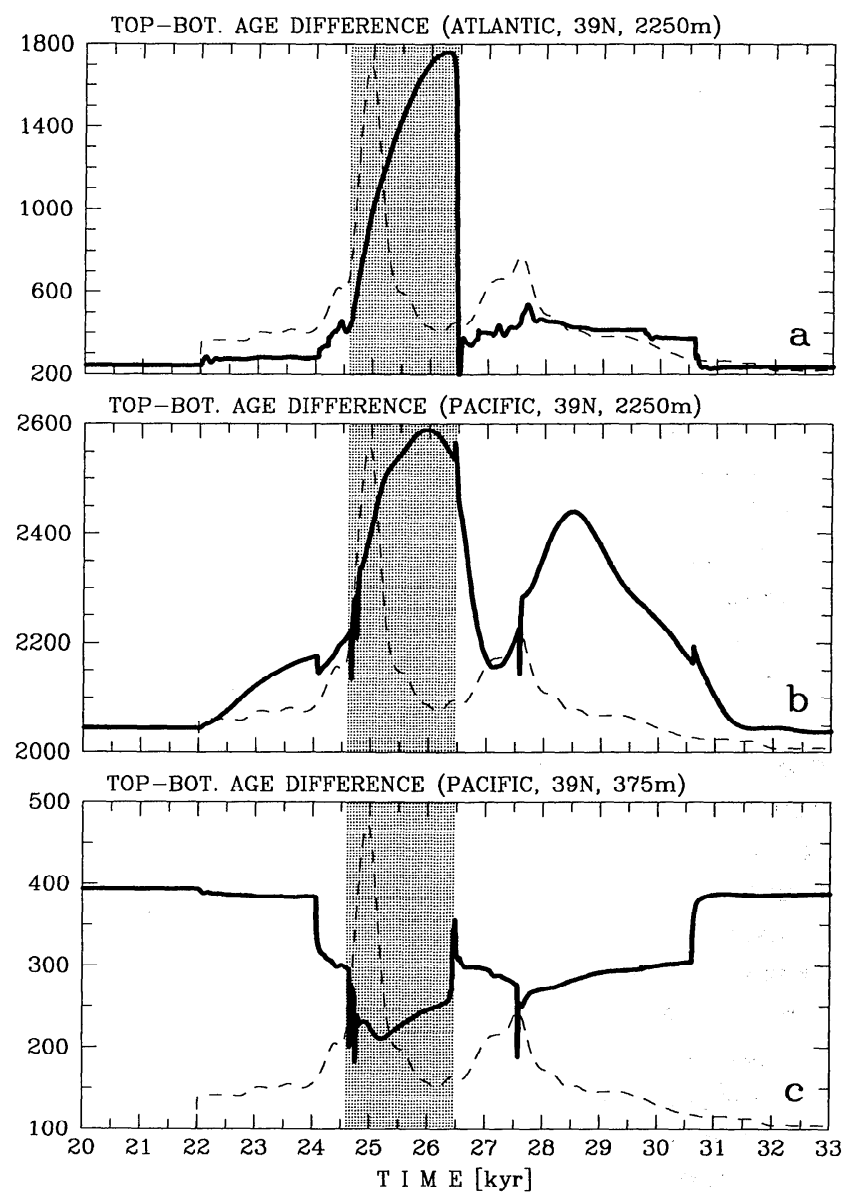

Figure 14. Evolution of the surface-to-bottom age dî́ference at $40^{\circ} \mathrm{N}$ for experiment T2. (a) In the deep Atlantic, the age difference increases by 1600 years due to the natural decay of the poorly ventilated deep water. (b) In the deep Pacific, the age difference increases by about 500 years primarily due to the increase of ${ }^{14} C^{\text {atm }}$. (c) At shallow depth, there is a dccrease of the age difference (in agreement with paleoclimatic data) because cooler air temperatures during YD increase the convection depth slightly. The period of YD is shaded.
Between shallower depths in the Pacific, there is actually a reduction of the age difference which can be related to an increase of convection at that location due to cooler surface air temperatures during the YD (Figure 14c). Although possibly fortuitous, it is remarkable that the data show exactly this effect. Kennet and Ingram [1995] analyze a sea sediment core of the Santa Barbara Basin (600 m depth) and find a reduction of the surfaceto-bottom age difference by about 300 years, argeeing well with the model estimate of a 200-year reduction. The sea surface temperature decrease during YD in the Pacific is moderate compared with that in the Atlantic, and no major circulation change is observed. Nevertheless, the lower SST changes the stability of the water column slightly and increases the convection depth at that latitude. This vertical mixing reduces the sufaceto-deep age difference and leaves a pronounced signal characteristic of YD. It should be emphasized that it would be incorrect to conclude from this finding alone that YD was also an important climatic event in the $\mathrm{Pa}$ cific region or that the ocean circulation had changed significantly there. At least for our model simulations, this is not the case.

\section{Observational Evidence of ${ }^{14} \mathrm{C}$ Plateaus and Age Differences}

The correspondence between climate change and age plateaus was first noticed in a peat bog and varved lake sediments where different paleoclimate indicators are determined at the same depth and hence are coeval [Oeschger et al., 1980; Zbinden et al., 1989]. Lotter [1991] analyzed a lake sediment core of the Swiss Rotsee and found two age plateaus in the radiocarbon stratigraphy. A first, shorter and weaker plateau is located around the Older Dryas/Bølling boundary (cold-to-warm transition) and extends into Bølling for a few centuries. The second, more pronounced plateau is found within YD and ends after the first step of $\delta^{18} \mathrm{O}$ and the first notable vegetation changes. From these cores, it appears that plateaus occur toward or at the end of cooler periods (Older and Younger Dryas). However, the end of YD is not very well defined in these cores.

Recent datings of the YD termination and their temporal relation with the radiocarbon chronology derived from tree rings are collected in Figure 1. The end of the Younger Dryas in the GRIP and GISPII (Greenland Ice Sheet Project Two) ice cores is dated at 11,500 \pm 70 [ Johnsen et al., 1992, S. Johnsen, personal communication, 1996] or $11,640 \pm 250$ calendar years yr B.P. [Alley et al., 1993]. A statistically equally compatible estimate for GISPII is $11,520 \pm 200$ calendar years yr B.P. [ Jouzel et al., 1995, R. Alley, personal communication, 1996], i.e., about 300 years before the end of the plateau found and dated in the tree rings. This result is in agreement with our model simulations. 
Becker et al. [1991] found that the plateau lies entirely within YD if the isotopic concentrations in the tree ring cellulose $\left(\delta^{13} \mathrm{C}\right.$ and $\left.\delta^{2} \mathrm{H}\right)$ are taken as indicators of warming at the termination of YD. However, $\delta^{13} \mathrm{C}$ and $\delta^{2} \mathrm{H}$ are more influenced by local humidity changes, and it appears that the tree ring widths are better indicators of the warming at the end of YD (S. Björck et al., submitted manuscript, 1996; B. Kromer, personal communication, 1996). The termination then occurs 11,480 calendar years yr B.P., which is a few hundred years before the end of the plateau (see Figure 1), in agreement with our model results. In addition, the chronology [Kromer and Becker, 1993] shows a sequence of plateaus in the early Holocene. It seems unlikely that all of these plateaus are due to changes of the ocean ventilation rate, since abrupt climatic events of YD amplitude are evidently absent in the Holocene. More likely mechanisms involve production changes [Beer et al., 1988]. Nevertheless, the longest period of reduced ${ }^{14} \mathrm{C}$ age increase is located near the end of YD, and it would be a fortuitous coincidence if it were of entirely nonoceanic origin.

Detailed isotopic and pollen analyses of Polish lake Gościąż show a $10,000{ }^{14} \mathrm{C}$ year plateau with a duration of about 250 years (based on their spline analysis). The plateau ends $100-200$ years after the termination of YD identified using $\delta^{18} \mathrm{O}$ [Goslar et al., 1995]. The YD termination is varve-dated at $11,410 \pm 120$ calendar years $\mathrm{yr}$ B.P. supporting the case of a plateau that extends beyond the YD/Preboreal boundary, as suggested by the present model simulations. Goslar et al. [1995] also find that atmospheric $\Delta^{14} \mathrm{C}$ was about $40 \%$ higher during YD. Our results strongly support their suggestion that this is consistent with significantly reduced ocean ventilation during YD.

The model results also suggest that ice cover may have played an important role during YD. A substantial increase of the surface reservoir ages, consistent with the observation of Bard et al. [1994], rcquircs that the extent of sea ice during YD was more southward in the Atlantic than simulated in the model. Ice cover also tends to increase the duration of the age plateau, and a sufficient length is only obtained in the model if sea ice is also present in the Southern Ocean during YD. Isotopic analysis of high-resolution cores from that area may give further clues.

The data make a strong case for the fact that a large portion of the $10,000{ }^{14} \mathrm{C}$ year plateau is of oceanic origin. Clearly, the search for "faithful" paleoclimatic archives from which both radiocarbon and climatic indicators are available must continue. Further progress depends critically on the availability of excellent timescales for these archives.

\section{Indications from the Meltwater Curve}

In this subsection, we examine alternative evidence for an oceanic influence on the radiocarbon clock which is based on our model results and the Fairbanks [1989] meltwater curve. For the model simulations, we have used the Fairbanks [1989] estimates of meltwater input based on radiocarbon dating of coral colonies and have chosen the parameter values of experiment C2. However, we have concluded that the dates may be influenced by variations of ${ }^{14} C^{\text {atm }}$ induced by changes in the ocean circulation. It is of interest to investigate the magnitude of the errors expected in the meltwater estimates due to errors in the age estimates. In the following discussion, we will use the fact that corals live near the surface of the ocean so they will experience variations in radiocarbon that closely follow those in the atmosphere.

If we assume that the timing errors in the meltwater estimates based on ${ }^{14} \mathrm{C}$ dating simply cause timing errors in our model response, then we can use the model results to estimate what the actual meltwater rates were. We first determine the corrected time axis. Then, to determine the corrected meltwater input rates, we use the fact that the estimated meltwater input rates are inversely proportional to the time interval between two sea level measurements.

Figure 15a shows the Fairbanks [1989] meltwater curve based on ${ }^{14} \mathrm{C}$ dating as a solid line and our estimate of the actual meltwater curve as a function of the corrected time as a broken line. While we certainly should not believe the details of this plot, the nature of the expected errors is evident. Near cach of the meltwater peaks, the uptake of ${ }^{14} C^{\mathrm{atm}}$ by the ocean is reduced and the radiocarbon clock runs too fast. As a result of the expanded time axis, the meltwater input rate appears to be slowed. According to our model, the Atlantic overturning is revitalized near year 26,470. At this time, the radiocarbon clock is slowed down to less than half speed, and consequently, the meltwater input rate appears to be more than double its actual value. The percentage changes in meltwater estimates are actually large during this latter period, but the small absolute meltwater rates cause this event to be overshadowed by the events associated with the meltwater peaks.

In Figure 15b, we make a direct comparison between the results of Fairbanks [1989] based on radiocarbon dating and those of Fairbanks [1990] based on U/Th dating of the same coral colonies. Comparison of Figure $15 \mathrm{a}$ and Figure $15 \mathrm{~b}$ is encouraging since it shows that the timing and magnitude of changes in the speed of the radiocarbon clock are reasonably estimated, at least during the periods when the clock speed is increased. Results are not as encouraging for the period 

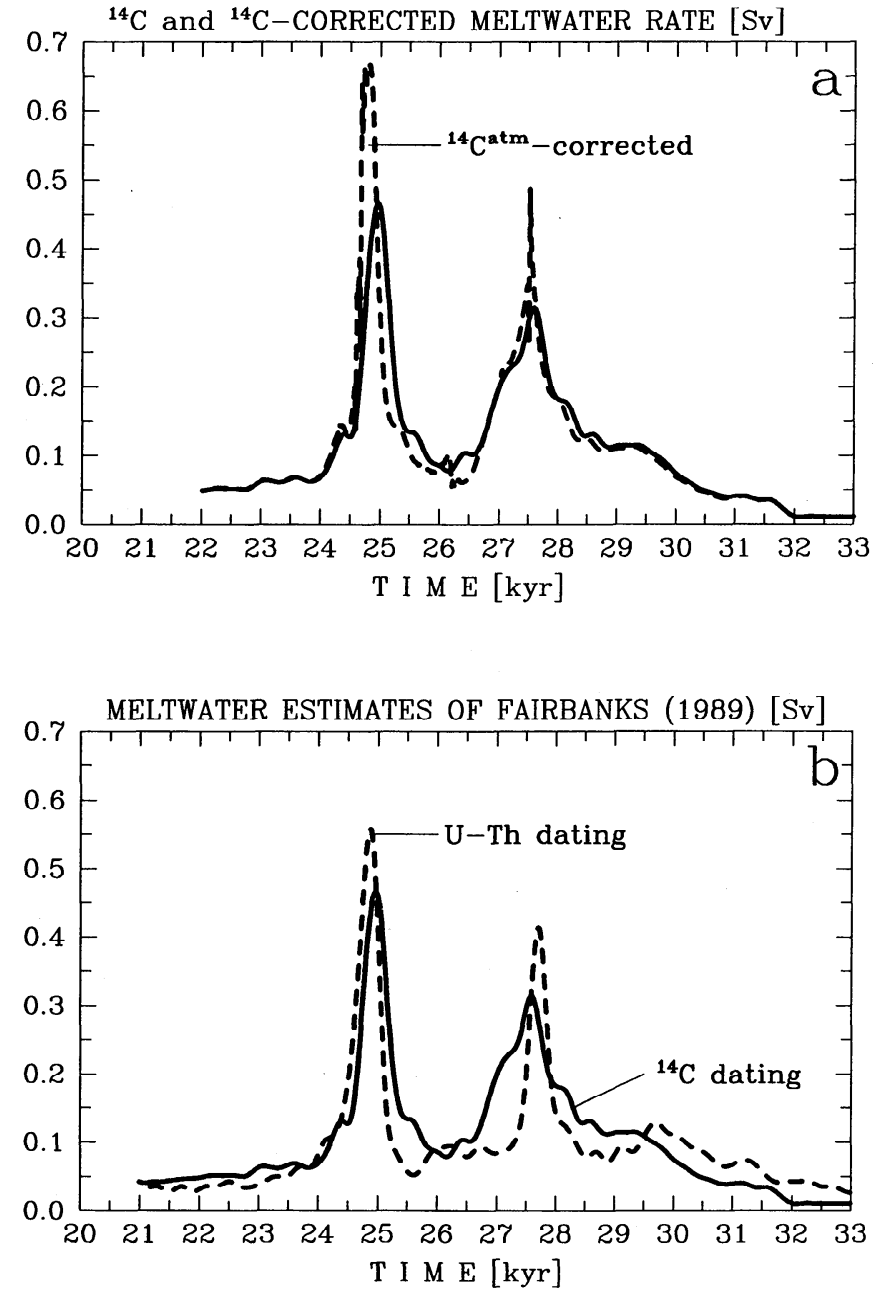

Figure 15. (a) The Fairbanks [1989] meltwater estimates based on ${ }^{14} \mathrm{C}$ dating of coral colonies (solid line), together with an estimate of the actual rate of meltwater input based on the ${ }^{14} \mathrm{C}$ curve and model results. (b) The Fairbanks [1989] meltwater estimates based on ${ }^{14} \mathrm{C}$ dating, together with the Fairbanks [1990] estimates based on U/Th dating. The long-term shift between the ${ }^{14} \mathrm{C}$ and the $\mathrm{U} / \mathrm{Th}$ timescale is not included.

when the clock is slowed down. However, the findings of Edwards et al. [1993] and Bard et al. [1996] strongly indicate that the observational estimates of meltwater input are very uncertain during this period. Note that we do not take into account changes in $F^{\text {cosm }}$, which are certainly important on timescales exceeding those of the meltwater peaks ( $\gtrsim 500$ years).

In the above discussion, we have followed previous investigations and based our model calculations on the original meltwater curves of Fairbanks [1989]. In doing so, we have assumed that the errors in the time axis do not greatly influence our results. To test this assumption, we have repeated the experiment corresponding to Figures $4-7$ but with the meltwater curve based on $\mathrm{U} / \mathrm{Th}$ dating. Our primary results on the influence of meltwater input are not significantly changed by using the improved estimates.

\section{Discussion and Conclusions}

Using an extended version of the physical-geochemical climate model of Stocker et al. [1994], we estimated the evolution of the atmospheric radiocarbon concentration resulting from transient changes in the global THC. The increase in atmospheric $\Delta^{14} \mathrm{C}$ during periods of reduced Atlantic overturning reaches approximately $35 \%$. Reestablishment of deep ocean ventilation in the NA results in a reduction of the atmospheric radiocarbon concentration, which is equivalent to a slowdown of the radiocarbon clock. The amplitude of this slowdown is a measure of the degree to which radiocarbon is depleted during the period of reduced circulation and the rapidity of the resumption of deep convection and the associated overturning circulation.

The model experiments suggest that the uptake of radiocarbon by the ocean was significantly slowed during both periods of meltwater input. The first meltwater pulse caused a cap of freshwater to form over the high-latitude NA, deep convection was shut off, and the Atlantic overturning circulation began to shallow and reduce in strength. As the production of deep water in the NA decreased, ${ }^{14} C^{\text {atm }}$ increased, and consequently, near-surface ocean values also increased due to gas exchange. Continued formation of $\mathrm{AABW}$ with higher ${ }^{14} \mathrm{C}$ concentrations and increased intrusion into the deep Atlantic act to limit the $\Delta^{14} \mathrm{C}$ reduction in the global ocean. In fact, in our model results, the radiocarbon clock was running slightly faster than normal even before the overturning circulation was renewed.

After about 1500 years of collapsed Atlantic overturning, convection is reinitiated at high latitudes and the present-day overturning is very rapidly reestablished. This process is encouraged by two effects: removal of the cap of freshwater from the surface layer of the $\mathrm{NA}$ and the gradual warming and salting of the deep ocean associated with an increased low-latitude influence. Since the surface freshening is very strong, significant increase of the surface salinity is required in order to reestablish the NA circulation and hence obtain a credible simulation of YD. In our model, this increase in surface salinity does not occur unless we reduce the net input of freshwater at high latitudes during YD. We find that reducing the background runoff to $25 \%$ of presentday estimates in the region north of $40^{\circ} \mathrm{N}$ is sufficient to obtain a realistic simulation. If the meltwater input is reduced to zero when the observational estimates of Fairbanks [1989] fall below $0.1 \mathrm{~Sv}$ (where the results of 
Edwards et al. [1993] show the estimates to be very uncertain), then only a $50 \%$ decrease in the background runoff is required to obtain a similar model simulation. The changes in deep water properties are secondary in reducing the large surface water to deep water density contrast that prevents high-latitude convection during the YD event. However, if the reduced circulation state persists long enough for deep ocean temperatures and salinities to increase significantly, then resumption is fast, with deep water formation accelerated by convective transport of warm saline water into the surface layer.

After the Atlantic overturning is reestablished, oceanic $\Delta^{14} \mathrm{C}$ quickly approaches the values prior to the initiation of meltwater input. This recovery is interrupted by the second meltwater pulse, but the overturning circulation is not greatly affected by this event. Following the second meltwater pulse, the radiocarbon clock is slowed by a few percent as the ocean inventory of radiocarbon gradually returns to initial levels over the next couple of thousand years.

To check the robustness of our results, we have done a number of additional experiments that have not been discussed above. First, several experiments were repeated with the dynamical formulation of Wright and Stocker [1992]; differences were generally quantitative rather than qualitative, so that none of our major conclusions would be changed if we had used the latter formulation. Wc repeated several of our runs without plumes in the Southern Ocean but with the Southern Ocean surface salinity increased during the initial spinup in order to produce reasonable deep water properties. Again, none of our major results were affected. Runs were also repeated with initial conditions consistent with the present-day ocean rather than with the higher initial values of salinity used in the experiments reported here. Again, the effects were of a secondary nature. We also performed a couple of experiments in which the thickness of the well-mixed surface region was not permitted to fall below $300 \mathrm{~m}$ in either the NA or the Southern Ocean. This was done in order to gain some feeling for the possible importance of mechanical stirring by wind stress. The minimum surface salinity obtaincd during the YD event in cell 15 of the NA increased from 32.6 to 32.8 , and the duration of the $\mathrm{YD}$ event was decreased by close to 400 years. This result suggests that the inclusion of a more sophisticated mixed-layer model might have a significant quantitative influence on our results, but the qualitative nature of the response was not changed. Finally, we reran a few experiments with the air-sea exchange of radiocarbon in the Southern Ocean rcduced by $50 \%$ so that the age of deep water in the Southern Ocean would be increased. This increased the initial values of $\Delta^{14} \mathrm{C}$ by about $20 \%$ in the Southern Ocean and resulted in ra- diocarbon variations that were 10 to $20 \%$ larger than in the experiments without this change, but again, our major conclusions were not affected.

The age plateau simulated by the model begins with the increase of NADW formation and persists for less than 100 years. If transient changes of the gas exchange rate or an extended ice cover (especially in the Southern Ocean) are taken into account, the duration of the age plateau increases to 150-300 years. Early data from varved lake sediments suggest that an age plateau began about halfway through YD and ended at the YD termination; this is not consistent with our model results. On the other hand, using the most recent date estimates of the YD termination, the age plateau is placed after YD. The model does not exhibit an increase of the surface reservoir ages in the NA but rather suggests that they were lower at the beginning of YD. This is because the convection which mixes deeper, older waters up into the surface layer is suppressed. However, after a few hundred years, equilibration with the atmosphere is reached and surface reservoir ages are again about 500 years. If sea ice cover is artificially extended during YD, the surface reservoir ages increase by $200-300$ years, consistent with the data.

Surface-to-bottom age differences are shown to have a great potential to provide more observational evidence for an oceanic origin of the YD event. An increase of the age difference by about 1600 years during YD is expected in the Atlantic. If correct, it should be possible to find this fingerprint in high-resolution sea sediments by analyzing planktonic and benthic forams at the same core. The YD event is also clearly identified in the Pacific region $\left(40^{\circ} \mathrm{N}\right)$ if one considers surface-to-bottom age differences. Because surface air temperature decreases by about $1.5^{\circ} \mathrm{C}$, the convection depth increases. Therefore the age difference between the original convecting surface layer and the underlying waters, which become part of the new convecting surface layer, is reduced. The model demonstrates that such isolated findings in paleoarchives do not allow the conclusion that circulation or climate have changed very significantly at that location.

Similarly, comparison of model results with the data sets of Fairbanks [1989] shows reasonable agreement with the timing and magnitude of changes in the radiocarbon clock during periods of reduced oceanic uptake, but the model and observational results are substantially different during the period when the ocean circulation is being reestablished. The results of $E d-$ wards et al. [1993] and Bard et al. [1996] demonstrate that the observational estimates still contain uncertainties, so all such comparisons should be interpreted cautiously. Improvements in the observational database, interpretations of these observations, and model simulations are all required. However, our present results 
generally support the assertion that changes in ocean circulation were sufficient to cause substantial changes in the radiocarbon clock.

\section{Appendix: Description of Model Components}

\section{Atmosphere}

The atmosphere component is the one-dimensional (zonally and vertically integrated) energy balance model of Stocker et al. [1992] and parameter values are given in Table A1.

\section{Ocean}

The ocean component is a three-basin zonally averaged ocean circulation model [Wright and Stocker, 1991; Wright and Stocker, 1992] with the improved closure scheme for the overturning velocity developed by Wright et al. [1995]. The new velocity closure requires a modification in the way the Southern Ocean is treated. Here we divide the Southern Ocean into three sectors, each of angular width $120^{\circ}$ identified with the three basins to the north. Between the sectors, we include north-south oriented barriers that extend from the ocean bottom to middepth $(2000 \mathrm{~m})$. Below the depth of the barriers, the parameterization is implemented as discussed by Wright et al. [1995]. Above the barriers, there can be no zonally averaged geostrophically balanced meridional circulation, and we thus assume that the only significant zonally averaged northsouth flow is in the surface Ekman layer. The first cell boundary within the Southern Ocean is thus effectively a barrier to geostrophic flow in the upper part of the water column, and we treat it as such in implementing the new closure scheme.
An additional modification made in the ocean component of the model is that we have allowed for vertical variations in the vertical diffusion coefficient [Weaver and Sarachik, 1991]:

$$
K_{v}=K_{v}^{0}\left[1-\frac{1.25}{\pi} \operatorname{atan}\left(\frac{z}{222.2 \mathrm{~m}}+11.25\right)\right] .
$$

The most important effect of this modification for the present study is that the lower near-surface diffusivity impedes the absorption of radiocarbon into the ocean in areas where convection does not dominate the vertical transfer. This results in a somewhat improved model simulation of the present-day distribution of radiocarbon in the ocean, especially in the Pacific. Parameters are given in Table A1.

\section{Sea Ice}

The sea ice component is the zero-layer sea ice model of Semtner [1976]; parameter va;lues are given in Table A2. The implementation is not significantly different from that discussed by Wright and Stocker [1993], except that the method of handling brine rejection during sea ice formation has also been modified. In reality, brine rejection due to seasonally varying sea ice cover plays an important role in the process of deep water formation, particularly around Antarctica and in the Arctic Ocean. However, in runs which do not include a seasonal cycle (as we consider here), this process is not modeled. Generally, in our model and in many others, this fact is compensated for by artificially increasing the salinity at the highest northern and southern latitudes so that water of the appropriate temperature and salinity is available to supply the deep ocean. This procedure is obviously not entirely satisfactory for several

Table A1. Ocean and Atmosphere Parameters

\begin{tabular}{lll}
\hline & Parameter & Value \\
\hline$\rho_{A}$ & surface air density & $1.225 \mathrm{~kg} \mathrm{~m}^{-3}$ \\
$h_{A}$ & atmosphere scale height & $8320 \mathrm{~m}$ \\
$H$ & ocean depth & $4000 \mathrm{~m}$ \\
$\Delta z$ & bottom depths of model cells & $50,100,150,250,500,750,1000,1250$, \\
& ridge height in Southern Ocean & $1500,2000,2500,3000,3500$, and $4000 \mathrm{~m}$ \\
$K_{v}$ & surface to bottom range of vertical diffusivity (see & $2000 \mathrm{~m}$ \\
& equation (A1)) & $1.27, \ldots, 0.31 \times 10^{-4} \mathrm{~m}^{2} \mathrm{~s}^{-1}$ \\
$K_{h}$ & horizontal diffusivity & $500 \mathrm{~m}^{2} \mathrm{~s}^{-1}$ \\
$D_{O A}$ & sensible heat exchange coefficient & $10 \mathrm{~W} \mathrm{~m}^{-2} \mathrm{~K}^{-1}$ \\
$\tau_{T}, \tau_{S}$ & relaxation time for T and $S$ & $50 \mathrm{days}$ \\
$\gamma_{1} \mathrm{a}$ & ocean velocity closure parameter & 1.1 \\
$\gamma_{2}{ }^{\mathrm{a}}$ & ocean velocity closure parameter & -0.6 \\
& & \\
\hline
\end{tabular}

a Determined by Wright et al. [1995]; $\gamma_{1}$ is associated with vorticity dissipation in the western boundary layer, and $\gamma_{2}$ is associated with the horizontal and vertical turning of the surface flow entering the northern boundary layer from the inviscid interior region. 
Table A2. Ice Parameters

\begin{tabular}{lll}
\hline & Parameter & Value \\
\hline$\rho_{i}$ & ice density $\left(0.9 \times \rho_{*}\right)$ & $925 \mathrm{~kg} \mathrm{~m}^{-3}$ \\
$q_{i}$ & latent heat of fusion & $3.34 \times 10^{5} \mathrm{~J} \mathrm{~kg}^{-1}$ \\
$K_{i}$ & ice conductivity & $2 \mathrm{~W} \mathrm{~m} \mathrm{~K}^{-1}$ \\
$T_{f}$ & freczing point of seawater & $S$ dependence from Gill $[1982]$ \\
$T_{m}$ & melting point & $-0.1^{\circ} \mathrm{C}$ \\
$e_{i}$ & ice surface longwave emissivity & 0.96 \\
$D_{i a}$ & ice-air sensible heat exchange coefficient & $10 \mathrm{Wm}^{-2} \mathrm{~K}^{-1}$ \\
\end{tabular}

reasons. For example, $E-P$ must be increased in order to maintain the surface salinity at the required level, and this may cause problems on coupling to an atmospheric model. Perhaps more important for the present study, if the surface salinity of the southernmost model cell is increased to the observed deep water value of order 34.7, convection in the Southern Ocean is usually vigorous, which leads to heavily ventilated AABW with radiocarbon concentrations that are significantly too high.

A simple representation of plumes has been included in order to account for the effect of brine rejection around Antarctica. We assume that a fraction of the salt cjected during sea ice formation is mixed with a specified volume of surface water, and we slot this new water in at its neutral stability level before calling the usual convection scheme. On the basis of an estimated annual mean sea ice formation rate of order $1 \mathrm{~Sv}$ [Hoffert, 1990; Budd, 1991], we take the salt from 0.5 Sv of water to go into plumes (a conservative estimate), and we mix it with a volume of surface water that would contain 50 times this much salt (chosen to give the resulting deep water a salinity consistent with present-day conditions). We emphasize that this approach can reasonably account for the effect of brine rejection in the presentday ocean, but it does not model it in a dynamically consistent manner. To do the latter, seasonal cycles are being incorporated now. Also note that the usual convection scheme [e.g., Wright and Stocker, 1992] is still employed after the "plume water" is slotted in at the appropriate depth level. Thus fixed plumes are included to allow for more realistic formation of AABW, but if the conservative amount of salt being removed from the surface layer via plumes is inadequate to yield a stable water column, any instabilities that remain are removed using the classical convective mixing scheme as in previous versions of the model.

\section{Biosphere}

The biosphere component is as described by Siegenthaler and Oeschger [1987]. It consists of four wellmixed compartments: ground vegetation and leaves, wood, detritus, and humus, each with different overturning times for carbon given in Table A3. The total carbon content of each reservoir and the fluxes of total carbon between the reservoirs and between the atmosphere and the reservoirs are fixed at the values of Siegenthaler and Oeschger [1987]. Fractionation factors for ${ }^{14} \mathrm{C}$ between atmosphere and biosphere are included in the model formulation, but since the model does not yet contain an organic carbon cycle model (presently under development) and we do not carry ${ }^{13} \mathrm{C}$, fractionation factors are all set to 1 . This is correct to first order in the fractionation factors if isotope ratios are interpreted directly as $\Delta^{14} \mathrm{C}$ (instead of carrying $\delta^{14} \mathrm{C}$ and $\delta^{13} \mathrm{C}$ in the model and then calculating $\Delta^{14} \mathrm{C}$ ).

Table A3. Radiocarbon and Biosphere Parameters

\begin{tabular}{|c|c|c|}
\hline & Parameter & Value \\
\hline$\lambda$ & ${ }^{14} \mathrm{C}$ decay constant & $3.833 \times 10^{-12} \mathrm{~s}^{-1}$ \\
\hline$R_{\text {std }}$ & standard ${ }^{14} \mathrm{C} /{ }^{12} \mathrm{C}$ ratio & $1.176 \times 10^{-12}$ \\
\hline$\Sigma_{0}^{M}$ & ocean reference concentration of total carbon & $2250 \mu \mathrm{mol} / \mathrm{kg}$ \\
\hline$p_{0}$ & preindustrial $p \mathrm{CO}_{2}$ & $280 \mathrm{ppm}$ \\
\hline$g_{0}$ & reference gas exchange rate & $7.131 \mathrm{~m} / \mathrm{yr}$ \\
\hline${ }^{14} C_{0}^{\mathrm{atm}}$ & ${ }^{14} \mathrm{C}$ restoring surface value & $13.92 \times 10^{-15} \mathrm{~mol} / \mathrm{m}^{3}($ at $280 \mathrm{ppm})$ \\
\hline \multirow{3}{*}{$F^{\operatorname{cosm}}$} & & $9.70 \times 10^{-15} \mathrm{~mol} / \mathrm{m}^{3}($ at $195 \mathrm{ppm})$ \\
\hline & cosmic flux of ${ }^{14} \mathrm{C}$ & 1.583 atoms $/\left(\mathrm{cm}^{2} \mathrm{~s}\right)($ at $280 \mathrm{ppm})$ \\
\hline & & 1.550 atoms $/\left(\mathrm{cm}^{2} \mathrm{~s}\right)($ at $195 \mathrm{ppm})$ \\
\hline
\end{tabular}




\section{Radiocarbon}

We have considered two different formulations for the net air-sea exchange of radiocarbon. The first approach calculates fluxes according to

$$
F^{A O}=\frac{H_{M}}{\tau}\left(\Delta^{14} C^{\mathrm{atm}}-\Delta^{14} C^{\mathrm{mix}}\right)
$$

where $H_{M}$ is the mixed-layer depth, $\tau$ is a specified restoring time, and $\Delta^{14} C^{\text {atm }}$ and $\Delta^{14} C^{\text {mix }}$ are model variables of the atmosphere and mixed-layer $\Delta^{14} \mathrm{C}$ values, respectively. To account for the long isotopic equilibration time, $\tau$ is about 5 years [Broecker and Peng, 1974; Toggweiler et al., 1989; Stocker et al., 1994].

The second method is based on the gas exchange formulation [Siegenthaler, 1983]:

$$
F^{A O}=g \alpha_{A O} \times{ }^{14} C^{\mathrm{atm}}-g \alpha_{O A} \xi \times{ }^{14} C^{\mathrm{mix}}
$$

where $\alpha_{A O}$ and $\alpha_{O A}$ are fractionation factors, ${ }^{14} C^{\text {atm }}$ and ${ }^{14} C^{\text {mix }}$ are the model variables of air and mixedlayer isotope concentrations in moles/kilogram, and $\xi$ is the buffer factor for radiocarbon (we use $\xi=1$, which is a good approximation, because in contrast to total carbon for which $\xi$ is of order 9 to 14 , the isotopic concentration is only weakly influenced by carbon chemistry). Here $g$ is a gas exchange rate given by

$$
g=k \times s \times \frac{p}{\Sigma_{0}^{M}}
$$

where $k$ denotes the piston velocity (in meters/second), $s$ denotes the solubility (in moles/(cubic meter ppm)), $p$ denotes the partial pressure of $\mathrm{CO}_{2}$ (in ppm) and $\Sigma_{0}^{M}$ denotes the reference concentration of total carbon in the mixed layer (in moles/cubic meter) [Broecker et al., 1985b]. All parameters are held constant except for $p$, which is allowed to vary during a deglaciation experiment due to the secular rise of $p \mathrm{CO}_{2}$ in the atmosphere. We employ

$$
g=g_{0} \frac{p}{p_{0}}
$$

where $g_{0}=7.313 \mathrm{~m} / \mathrm{yr}$ is the gas exchange rate at the preindustrial $p \mathrm{CO}_{2}$ concentration, and $p$ and $p_{0}$ are actual and preindustrial atmospheric partial pressures of $\mathrm{CO}_{2}$, respectively.

In all experiments presented in this paper, we have used the second, more accurate, formulation. Transient experiments using both formulations have shown only minor differences for cases in which the atmospheric partial pressure of $\mathrm{CO}_{2}$ is held constant. However, our experiments with $p$ changing according to reconstructions from an Antarctic ice core show that variations in atmospheric $\mathrm{CO}_{2}$, which are accounted for in only the second formulation, can significantly affect results.
We calculate $\Delta^{14} \mathrm{C}$ according to

$$
\Delta^{14} \mathrm{C}=1000 \% \times \frac{{ }^{14} C / \Sigma-R_{\text {std }}}{R_{\text {std }}},
$$

where ${ }^{14} C$ is the radiocarbon concentration, $\Sigma$ is a reference concentration of total carbon in the respective reservoir, and $R_{\text {std }}$ is the standard ${ }^{14} \mathrm{C} /{ }^{12} \mathrm{C}$ ratio. Therefore we neglect the correction for isotopic fractionation. This is correct to first order (in the fractionation factors) if the fractionation factors $\alpha_{A O}$ and $\alpha_{O A}$ are set to 1 .

Since there are uncertainties in the gas exchange rate $g_{0} \quad$ [Wanninkhof, 1992], we have performed two additional experiments with $g_{0}=3.7$ and $11 \mathrm{~m} / \mathrm{yr}$ and all other parameters as in experiment $\mathrm{C} 2$. The value of $g_{0}=7.13 \mathrm{~m} / \mathrm{yr}$ [Broecker et al., $1985 \mathrm{~b}$ ] gives an oceanic $\Delta^{14} \mathrm{C}$ distribution that is broadly consistent with the modern distribution, whereas the additional two experiments show generally too low or too high $\Delta^{14} \mathrm{C}$ values, respectively. The influence on the length of the plateau is minor: It increases from 40 to 64 years when increasing $g_{0}$ from $3.7 \mathrm{~m} / \mathrm{yr}$ to $11 \mathrm{~m} / \mathrm{yr}$. More important are temporal changes of $g$ due to ice cover, wind speed, and temperature changes, as indicated by sets $T$ and $I$ of the experiments in Table 1.

Acknowledgments. We enjoyed discussions with $\mathrm{W}$. Broecker, F. Joos, B. Kromer, I. Hajdas, R. Alley, E. Bard, and T. Blunier. We are indebted to B. Kromer, who provided the new radiocarbon calibration curve. The comments of U. Mikolajewicz, K. Caldeira, and an anonymous reviewer have improved the presentation. This study was initiatcd under grant DE-FG02-91ER61202 of the U.S. Department of Energy and is made possible by the Swiss National Science Foundation, the University of Bern, and funding from the Climate System History and Dynamics project funded by the Natural Science and Engineering Research Council, Canada. This is Lamont Doherty Earth Observatory contribution Nr. 5548 .

\section{References}

Alley, R. B., et al., Abrupt increase in Greenland snow accumulation at the end of the Younger Dryas event, $\mathrm{Na}$ ture, 362, 527-529, 1993.

Bard, E., B. Hamelin, R. G. Fairbanks, and A. Zindlcr, Calibration of the ${ }^{14} \mathrm{C}$ timescale over the past 30,000 years using mass spectrometric U-Th ages from Barbados corals, Nature, 345, 405-409, 1990.

Bard, E., M. Arnold, J. Mangerud, M. Paterne, L. Labeyrie, J. Duprat, M.-A. Mélières, E. Sønstegaard, and J.-C. Duplessy, The North Atlantic atmosphere-sea surface ${ }^{14} \mathrm{C}$ gradient during the Younger Dryas climatic event, Earth Planet. Sci. Lett., 126, 275-287, 1994.

Bard, E., B. Hamelin, M. Arnold, L. Montaggioni, G. Cabioch, G. Faure, and F. Rougerie, Deglacial sealevel record from Tahiti corals and the timing of global meltwater discharge, Nature, 382, 241-244, 1996.

Baumgartner, A., and E. Reichel, The World Water Balance, 179 pp., Elsevier, New York, 1975.

Becker, B., B. Kromer, and P. Trimborn, A stable-isotope 
tree-ring timescale of the Late Glacial/Holocene boundary, Nature, 353, 647-649, 1991.

Beer, J., U. Siegenthaler, G. Bonani, R. C. Finkel, H. Oeschger, M. Suter, and W. Wölfli, Information on past solar activity and geomagnetism from ${ }^{10} \mathrm{Be}$ in the Camp Century ice core, Nature, 331, 675-679, 1988.

Blunier, T., J. Chappellaz, J. Schwander, B. Stauffer, and D. Raynaud, Variations in the atmospheric methane concentration during the Holocene, Nature, 374, 46-49, 1995.

Bond, G., W. S. Broecker, S. J. Johnsen, J. McManus, L. Labeyrie, J. Jouzel, and G. Bonani, Correlations between climate records from North Atlantic sediments and Greenland ice, Nature, 365, 143-147, 1993.

Broecker, W. S., Massive iceberg discharges as triggers for global climate change, Nature, 372, 421-424, 1994.

Broecker, W. S., and G. H. Denton, The role of oceanatmosphere reorganizations in glacial cycles, Geochim. Cosmochim. Acta, 53, 2465-2501, 1989.

Broecker, W. S., and T.-H. Peng, Gas exchange rates between air and sea, Tellus, 26, 21-35, 1974.

Broecker, W. S., D. Peteet, and D. Rind, Does the oceanatmosphere system have more than one stable mode of operation ?, Nature, 315, 21-25, 1985a.

Broecker, W. S., T.-H. Peng, G. Östlund, and M. Stuiver, The distribution of bomb radiocarbon in the ocean, $J$. Geophys. Res., 90, 6953-6970, 1985b.

Broecker, W. S., M. Andree, W. Wölfli, H. Oeschger, G. Bonani, J. Kennett, and D. Peteet, The chronology of the last deglaciation: Implications to the cause of the Younger Dryas event, Paleoceanography, 3, 1-19, 1988.

Bryan, F., High-latitude salinity effects and interhemispheric thermohaline circulations, Nature, 323, 301-304, 1986.

Budd, W. F., $\Lambda$ ntarctica and global change, Clim. Change, 18, 271-299, 1991.

Chappellaz, J., T. Blunier, D. Raynaud, J. M. Barnola, J. Schwander, and B. Stauffer, Synchronous changes in atmospheric $\mathrm{CH}_{4}$ and Greenland climate between 40 and 8 kyr BP, Nature, 366, 443-445, 1993.

Clark, P. U., R. B. Alley, L. D. Keigwin, J. M. Licciardi, S. J. Johnsen, and H. Wang, Origin of the first global meltwater pulse, Paleoceanography, 11, 563-577, 1996.

Damon, P. E., J. C. Lerman, and A. Long, Temporal fluctuations of atmospheric ${ }^{14} \mathrm{C}$ : Causal factors and implications, Annu. Rev. Earth Planet. Sci., 6, 457-494, 1978.

Dansgaard, W., J. W. C. White, and S. J. Johnsen, The abrupt termination of the Younger Dryas climate event, Nature, 339, 532-534, 1989.

Denton, G. H., and C. H. Hendy, Younger Dryas age advance of Franz Josef glacier in the southern alps of New Zealand, Science, 264, 1434-1437, 1994.

Duplessy, J.-C., N. J. Shackleton, R. G. Fairbanks, L. Labeyrie, D. Oppo, and N. Kallel, Deepwater source variations during the last climate cycle and their impact on the global deepwater circulation, Paleoceanography, 3, 343-360, 1988.

Edwards, R. L., W. J. Beck, G. S. Burr, D. J. Donahue, J. M. A. Chappell, A. L. Bloom, E. R. M. Druffel, and F. W. Taylor, A large drop in atmospheric ${ }^{14} \mathrm{C} /{ }^{12} \mathrm{C}$ and reduced melting in the Younger Dryas, documented with ${ }^{230} \mathrm{Th}$ ages of corals, Science, 260, 962-968, 1993.

Fairbanks, R. G., A 17,000 year glacio-eustatic sea-level record: Influence of glacial melting rates on the Younger Dryas event and deep ocean circulation, Nature, 342,637$642,1989$.

Fairbanks, R. G., The age and origin of the "Younger Dryas climate event" in Greenland ice cores, Paleoceanography, 5, 937-948, 1990.

Gill, A. E., Almosphere-Ocean Dynamics, Int. Geophys. Ser., vol. 30, 662 pp., Academic, San Diego, Calif., 1982. Goslar, T., et al., High concentration of atmospheric ${ }^{14} \mathrm{C}$ during the Younger Dryas cold episode, Nature, 377, 411417, 1995.

Hajdas, I., S. D. Ivy, J. Beer, G. Bonani, D. Imboden, A. F. Lotter, M. Sturm, and M. Suter, AMS radiocarbon dating and varve chronology of Lake Soppensee: 6000 to 12,000 ${ }^{14} \mathrm{C}$ years BP, Clim. Dyn., 9, 107-116, 1993.

Hammer, C. U., H. B. Clausen, and C. C. Langway, Electrical conductivity method (ECM) stratigraphic dating of the Byrd Station ice core, Antarctica, Ann. Glaciol., 20, 115-120, 1994.

Han, Y. J., and S. W. Lee, An analysis of monthly mean windstress over the global ocean, Mon. Weather Rev., 111, 1554-1566, 1983.

Hoffert, M. I., Climate change and ocean bottom water formation: Are we missing something?, in Climate-Ocean Interaction, edited by M. E. Schlesinger, pp. 295-317, Kluwer Academic, Norwell, Mass., 1990.

Jansen, E., and T. Veum, Evidence for two-step deglaciation and its impact on North Atlantic deep-water circulation, Nature, 343, 612-616, 1990.

Johnsen, S. J., H. B. Clausen, W. Dansgaard, K. Fuhrer, N. Gundestrup, C. U. Hammer, P. Iversen, J. Jouzel, B. Stauffer, and J. P. Steffensen, Irregular glacial interstadials recorded in a new Greenland ice core, Nature, 359, 311-313, 1992.

Jouzel, J., et al., The two-step shape and timing of the last deglaciation in Antarctica, Clim. Dyn., 11, 151-161, 1995.

Keigwin, L. D., and S. J. Lehman, Deep circulation change linked to Heinrich event 1 and Younger Dryas in a middepth North Atlantic core, Paleoceanography, 9, 185-194, 1994.

Kennet, J. P., and L. B. Ingram, A 20,000-year record of ocean circulation and climate change from the Santa Barbara basin, Nature, 377, 510-514, 1995.

Koç, N., E. Jansen, and H. Haflidason, Paleoceanographic reconstructions of surface ocean conditions in the Greenland, Iceland and Norwegian Seas through the last $14 \mathrm{ka}$ based on diatoms, Quat. Sci. Rev., 12, 115-140, 1993.

Kromer, B., and B. Becker, German oak and pine ${ }^{14} \mathrm{C}$ calibration, 7200-9439 вC, Radiocarbon, 35, 125-135, 1993.

Kromer, B., and B. Becker, Tree-rings, absolute chronology and climatic change, Eur. Rev., 3, 303-308, 1995.

Lehman, S. J., and L. D. Keigwin, Sudden changes in North Atlantic circulation during the last deglaciation, Nature, 356, 757-762, 1992.

Lehman, S. J., D. G. Wright, and T. F. Stocker, Transport of freshwater into the deep ocean by the convcyor, in Ice in the Climate System, edited by W. R. Peltier, NATO ASI Ser., Ser. I, 12, 187-209, 1993.

Levitus, S., Climatological atlas of the world ocean, NOAA Prof. Pap. 13, 173 pp., U. S. Govt. Print. Office, Washington, D.C., 1982.

Lotter, A. F., Absolute dating of the late-glacial period in Switzerland using annually laminated sediments, Quat. Rev., 35, 321-330, 1991.

Mabin, M. C. G., The age of the Waiho Loop glacial event, Science, 271, 668, 1996.

Maier-Reimer, E., and U. Mikolajewicz, Experiments with an OGCM on the cause of the Younger Dryas, Tech. Rep. 39, pp. 1-13, Max-Planck-Inst. für Meteorol., Hamburg, Germany, 1989. 
Manabe, S., and R. J. Stouffer, Two stable equilibria of a coupled ocean-atmosphere model, J. Clim., 1, 841-866, 1988.

Manabe, S., and R. J. Stouffer, Century-scale effects of increased atmospheric $\mathrm{CO}_{2}$ on the ocean-atmosphere systcm, Nature, 364, 215-218, 1993.

Manabe, S., and R. J. Stouffer, Simulation of abrupt climate change induced by freshwater input to the North Atlantic Ocean, Nature, 378, 165-167, 1995.

Mikolajewicz, U., and E. Maier-Reimer, Mixed boundary conditions in ocean general circulation models and their influence on the stability of the model's conveyor belt, $J$. Geophys. Res., 99, 22,633 22,644, 1994.

Neftel, A., H. Oeschger, 'I'. Staffelbach, and B. Stauffer, $\mathrm{CO}_{2}$ record in the Byrd ice core 50,000-5,000 years BP, Nature, 331, 609-611, 1988.

Oeschger, H., J. Beer, U. Siegenthaler, B. Stauffer, W. Dansgaard, and C. C. Langway, Late glacial climate history from ice cores, in Climate Processes and Climate Sensitivity, Geophys. Monogr. Ser., vol. 29, edited by J. E. Hansen and 'T. Takahashi, pp. 299-306, AGU, Washington, D. C., 1984.

Oeschger, H., M. Welten, U. Eicher, M. Möll, T. Riesen, U. Siegenthaler, and S. Wegmüller, ${ }^{14} \mathrm{C}$ and other parameters during the Younger Dryas cold phase, Radiocarbon, 22, 299-310, 1980.

Peltier, W. R., Ice age paleotopography, Science, 265, 195201, 1994.

Peng, T.-H., Changes in ocean ventilation rates over the last 7000 years based on ${ }^{14} \mathrm{C}$ variations in the atmosphere and oceans, Radiocarbon, 31, 481-492, 1989.

Rahmstorf, S., Rapid climate transitions in a coupled oceanatmosphere model, Nature, 372, 82-85, 1994.

Sakai, K., and W. R. Peltier, A multibasin reduced model of the global thermohaline circulation: Paleoceanographic analyses of the origins of ice-age climate variability, $J$. Geophys. Res., in press, 1996.

Sarnthein, M., K. Winn, S. J. A. Jung, J.-C. Duplessy, L. Labeyrie, H. Erlenkeuser, and G. Ganssen, Changes in east Atlantic deepwater circulation over the last 30,000 years: Eight time slice reconstructions, Paleoceanography, 9, 209-267, 1994.

Semtner, A. J., A model for the thermodynamic growth of sea ice in numerical investigations of climate, $J$. Phys. Oceanogr., 6, 379-389, 1976.

Siegenthaler, U., Uptake of excess $\mathrm{CO}_{2}$ by an outcropdiffusion model of the ocean, J. Geophys. Res., 88, 35993608, 1983.

Siegenthaler, U., and H. Oeschger, Biospheric $\mathrm{CO}_{2}$ emissions during the past 200 years reconstructed by convolution of ice core data, Tellus, Ser. B, 39, 140-154, 1987.

Siegenthaler, U., M. Heimann, and $H$. Oeschger, ${ }^{14} \mathrm{C}$ variations caused by changes in the global carbon cycle, $R a$ diocarbon, 22, 177-191, 1980.

Staffelbach, T., B. Stauffer, A. Sigg, and H. Oeschger, $\mathrm{CO}_{2}$ measurcments from polar ice cores: More data from different sites, Tellus, Ser. B, 43, 91-96, 1991.

Stocker, T. F., D. G. Wright, and L. A. Mysak, A zonally averaged, coupled ocean-atmosphere model for paleoclimate studies, J. Clim., 5, 773-797, 1992.
Stocker, T. F., W. S. Broecker, and D. G. Wright, Carbon uptake experiments with a zonally-averaged global ocean circulation model, Tellus, Ser. B, 46, 103-122, 1994.

Stuiver, M., and T. F. Braziunas, Modeling atmospheric ${ }^{14} \mathrm{C}$ influences and ${ }^{14} \mathrm{C}$ ages of marine samples to 10,000 BC, Radiocarbon, 35, 137-189, 1993.

Taylor, K. C., G. W. Lamorey, G. A. Doyle, R. B. Alley, P. M. Grootes, P. A. Mayewski, J. W. C. White, and L. K. Barlow, The 'flickering switch' of late Pleistocene climate change, Nature, 361, 432-436, 1993.

Toggweiler, J., and B. Samuels, New radiocarbon constraints on the upwelling of abyssal water to the ocean's surface, in The Global Carbon Cycle, edited by M. Heimann, NATO ASI Ser., Ser. I, 15, 333-366, 1993.

Toggweiler, J. R., K. Dixon, and K. Bryan, Simulation of radiocarbon in a coarse-resolution world ocean model, 2 , Distributions of bomb-produced carbon 14, J. Geophys. Res., 94, 8243-8264, 1989.

Veum, T., E. Jansen, M. Arnold, I. Beyer, and J.-C. Duplessy, Water mass exchange between the North Atlantic and the Norwegian Sea during the past 28,000 years, $\mathrm{Na}$ ture, 356, 783-785, 1992.

Wanninkhof, R., Relationship between wind speed and gas exchange over the ocean, J. Geophys. Res., 97, 7373-7382, 1992.

Weaver, A. J., and E. S. Sarachik, The role of mixed boundary conditions in numerical models of the ocean's climate, J. Phys. Oceanogr., 21, 1470-1493, 1991.

Wright, D. G., and T. F. Stocker, A zonally averaged ocean model for the thermohaline circulation. Part I: Model development and flow dynamics, J. Phys. Oceanogr., 21, 1713-1724, 1991.

Wright, D. G., and T. F. Stocker, Sensitivities of a zonally averaged global ocean circulation model, J. Geophys. Res., 97, 12,707-12,730, 1992.

Wright, D. G., and T. F. Stocker, Younger Dryas experiments, in Ice in the Climate System, edited by W. R. Peltier, NATO ASI Ser., Ser. I, 12, 395-416, 1993.

Wright, D. G., C. B. Vreugdenhil, and T. M. Hughes, Vorlicity dynamics and zonally averaged ocean circulation models, J. Phys. Oceanogr., 25, 2141-2154, 1995.

Zbinden, H., M. Andree, H. Oeschger, B. Ammann, A. Lotter, G. Bonani, and W. Wölfli, Atmospheric radiocarbon at the end of the last glacial: An estimate based on $\Lambda \mathrm{MS}$ radiocarbon dates on terrestrial macrofossils from lake sediments, Radiocarbon, 31, 795-804, 1989.

Zhang, S., R. Greatbatch, and C. A. Lin, A reexamination of the polar halocline catastrophe and implications for coupled ocean-atmosphere modeling, J. Phys. Oceanogr., 23, 287-299, 1993.

T. F. Stocker, Climate and Environmental Physics, Physics Institute, University of Bern, Sidlerstr. 5, 3012 Bern, Switzerland. (email: stocker@climate.unibe.ch)

D. G. Wright, Department of Fisheries and Oceans, Bedford Institute of Oceanography, Dartmouth, Nova Scotia, B2Y 4A2, Canada. (email: dwright@emerald.bio.dfo.ca)

(Received March 19, 1996; revised August 22, 1996; accepted August 27, 1996.) 